\title{
Organic-inorganic hybrid sol-gel coatings for metal corrosion protection: a review of recent progress
}

\author{
R. B. Figueira, C. J. R. Silva, E. V. Pereira
}

(C) American Coatings Association 2014

\begin{abstract}
This paper is a review of the most recent and relevant achievements (from 2001 to 2013) on the development of organic-inorganic hybrid $(\mathrm{OIH})$ coatings produced by sol-gel-derived methods to improve resistance to oxidation/corrosion of different metallic substrates and their alloys. This review is focused on the research of $\mathrm{OIH}$ coatings based on siloxanes using the sol-gel process conducted at an academic level and aims to summarize the materials developed and identify perspectives for further research. The fundamentals of sol-gel are described, including $\mathrm{OIH}$ classification, the interaction with the substrate, their advantages, and limitations. The main precursors used in the synthesis of $\mathrm{OIH}$ sol-gel coatings for corrosion protection are also discussed, according to the metallic substrate used. Finally, a multilayer system to improve the resistance to corrosion is proposed, based on $\mathrm{OIH}$ coatings produced by the sol-gel process, and the future research challenges are debated.
\end{abstract}

Keywords Coatings, Organic-inorganic hybrids, Corrosion, Sol-gel method

$\begin{array}{ll}\text { Abbreviations } \\ \text { AEA } & \text { Aliphatic epoxy acrylate } \\ \mathrm{Al}\left(\mathrm{O}^{\mathrm{s}} \mathrm{Bu}\right)_{3} & \text { Aluminum tri-sec-butoxide } \\ \mathrm{BTAH} & 1,2,3 \text {-Benzotriazole } \\ \mathrm{BTMS} & n \text {-Butyltrimethoxysilane } \\ \mathrm{CCCs} & \text { Chemical conversion coatings } \\ \text { DETA } & \text { Diethylenetriamine }\end{array}$

R. B. Figueira (凶), E. V. Pereira

Laboratório Nacional de Engenharia Civil (LNEC),

Av. Brasil 101, 1700-066 Lisbon, Portugal

e-mail: rmfigueira@lnec.pt

R. B. Figueira, C. J. R. Silva

Centro de Química, Universidade do Minho, Campus de

Gualtar, 4710-057 Braga, Portugal

$\begin{array}{ll}\text { DGEBA } & \text { Poly(bisphenol A-co-epichlorohydrin) } \\ \text { DMTMS } & \text { Dimethyltrimethoxysilane } \\ \text { ECO } & \text { Epoxidized castor oil } \\ \text { EGDMA } & \text { Ethyleneglycoldimethacrylate } \\ \text { ER } & \text { Epoxy resin } \\ \text { ERE } & \text { Epoxy-resin-ester } \\ \text { GMA } & \text { Glycidylmethacrylate } \\ \text { HDGS } & \text { Hot-dip galvanized steel } \\ \text { HEMA } & \text { 2-Hydroxyethylmethacrylate } \\ \text { HMDIC } & \text { Hexamethylene diisocyanate } \\ \text { HMDS } & \text { Hexamethyldisilozane } \\ \text { HEPA } & \text { 2,2'-Bis(4- } \beta \text {-hydroxy ethoxy) phenyl } \\ & \text { propane } \\ \text { HTMS } & n \text {-Hexyltrimethoxysilane } \\ \text { IBTMS } & \text { Isobutyltrimethoxysilane } \\ \text { IOTMS } & \text { Isooctyltrimethoxysilane } \\ \text { IPDIC } & \text { Isophorone diisocyanate } \\ \text { LDF } & \text { Linseed diol fattyamide } \\ \text { MAEP } & \text { 2-Methacryloyloxyethylphosphate } \\ \text { MAPTES } & \text { 3-Methacryloxy propyl triethoxysilane } \\ \text { MMA } & \text { Methylmethacrylate } \\ n \text {-PTMS } & n \text {-Propyl trimethoxysilane } \\ \text { OIH } & \text { Organic-inorganic hybrid } \\ \text { OTES } & \text { Octyltriethoxysilane } \\ \text { OTMS } & \text { Octyltrimethoxysilane } \\ \text { PAPTES } & N \text {-Phenyl-3-aminopropyltriethoxysilane } \\ \text { PDMSU } & \text { Bis[(ureapropyl)triethoxysilane] } \\ & \text { bis(propyl)-terminated- } \\ \text { PDMMS } & \text { polydimethylsiloxane 1000 } \\ \text { PFOTES } & \text { 1H,1H,2H,2H-Per-fluorooctyltriethoxysilane } \\ \text { PR } & \text { Polyester resin } \\ \text { SiO } \text {-NP } & \text { Silica nanoparticles } \\ \text { SNAP } & \text { Self-assembled nanophase particle } \\ & \end{array}$




$\begin{array}{ll}\text { TBADP } & \text { Titanium(IV)-bis(acac)diisopropoxide } \\ \text { TDIC } & \text { Toluene diisocyanate } \\ \text { TEPA } & \text { Tetraethylenepentamine } \\ \text { TETA } & \text { Triethylenetetramine } \\ \text { TIBMS } & \text { Triisobutoxy(methyl)silane } \\ \text { TIPMS } & \text { Triisopropoxy(methyl)silane } \\ \text { TMCS } & \text { Trimethylchlorosilane } \\ \text { TMSPh } & \text { Tris-(trimethylsilyl)phosphate } \\ \text { ZrBTO } & \text { Zirconium(IV) butoxide }\end{array}$

\section{Introduction}

Corrosion protection of metallic substrates using coatings is an active and important research area in materials science and in industry. Through the application of coatings, corrosion can be minimized and controlled by one of three main mechanisms (or by a combination of these), namely a barrier effect preventing the contact between the corrosive medium and the metallic substrate and preventing ion migration among the coatings; a cathodic protection where the coating material acts as a sacrificial anode; the use of inhibition/passivation species, including cases of anodic or/and cathodic protection, that inhibit the action of the external corrosive agents.

Technological development has led to the production of a large variety of coatings and materials that have an efficient barrier effect preventing corrosion, namely inorganic coatings, paints, and other surface treatments. Chromate and similar hexavalent chromium compounds are effective substances used as inhibitors and are usually incorporated in anticorrosive pretreatments of a wide range of metals and alloys. The high corrosion resistance offered by the use of chromate films is due to the presence of $\mathrm{Cr}^{6+}$ ions. One important example is chromate-based chemical conversion coatings (CCCs), as this surface treatment shows an enhanced corrosion resistance and improves coating adhesion. Nonetheless, the use of hazardous compounds, such as CCCs, volatile organic compounds (VOCs), and hazardous air pollutants (HAPs), has been restricted after studies about their impact on natural environments and human health showed them to be toxic and carcinogenic. As such, their application is heavily regulated by most environmental legislation.

The need for alternative environmental friendly materials and processes has been investigated, leading to an enormous effort in the search for novel materials. These materials must provide good corrosion protection performance as well the recommended environmental targets. During this period, researchers from civil and mechanical engineering, chemistry, materials, and corrosion sciences have tested a large variety of nontoxic and environmentally friendly processes and among them the sol-gel method has demonstrated to be an efficient alternative for the replacement of existing CCC technology.

Osborne $^{1}$ in 2001 reported the application of solgel methods for the production of gel coatings for metal corrosion protection purposes. The article entitled "Some observations on chromate conversion coatings from a sol-gel perspective" confirmed that new chromate-free materials obtained by sol-gel methods allowed flexible control of coating morphology and constituent oxide materials leading to enhanced properties of the conversion coatings. This report showed that the organic-inorganic hybrid $(\mathrm{OIH})$ coatings produced exhibited promising properties of adhesion and corrosion protection. The obtained data also suggested that the $\mathrm{OIH}$ gel formulation might be tuned to contain nonsoluble chromium inhibitors regulating their effective concentrations within the coating layer. ${ }^{1}$ The quick evolution of this specific research area and the potential contribution of sol-gel coatings as a corrosion inhibition system for metal substrates has led to several review publications. ${ }^{2,3}$ As alternatives to the use of chromate for corrosion protection of aluminum aerospace alloys ${ }^{4}$ the use of sol-gel-derived coatings for improved corrosion resistance of aluminum and steel metal surfaces ${ }^{5,6}$ and magnesium alloys ${ }^{7}$ had also been debated.

OIHs obtained by sol-gel methods are a new generation of multifunctional materials with a broad spectrum of useful properties and a diversity of application potential. The name itself indicates the presence of both organic and inorganic components within the common matrix support. The inorganic part is formed from silicon or transition metal alkoxides via hydrolysis, while the organic part could be based on a diversity of molecules, and depending on how the matrix structure is produced, they can be segments of a quasi-continuous macromolecular domains grafting or bonding the inorganic skeleton. These two components (hydrophilic oxides and hydrophobic organic molecules) are normally difficult to combine within the composite network, and to achieve the interaction between them special reaction conditions must be applied.

The sol-gel $\mathrm{OIH}$ coatings are complex matrices where the intermolecular interactions between the macromolecular existing structures and metallic surface are extremely relevant to material properties, like low porosity and rigidity and adhesion to substrate. The conjugation of these interactions results in materials with enhanced protective properties against oxidation, corrosion, erosion, and good thermal and electrical insulation properties. Another technological advantage of these materials arises from their ability to be produced at room temperature conditions on an industrial scale using well established and low-cost methods like spray, dip and spin coating, flow coating, 
roll coating, doctor blading, and capillary coating processes or using any combination thereof. ${ }^{8}$ Altogether, the reagents involved to produce such matrices have very low environmental impacts. The tested corrosion protection processes and materials based on sol-gel technology demonstrate positive performances when several properties are considered, such as corrosion resistance, adhesion, fatigue resistance, reliability, and quality control. Although some of the possible alternatives demonstrate promise for corrosion protection, continuous efforts are being made in improving the production of $\mathrm{OIH}$ materials with improved properties, the understanding of the mechanisms involved in coating production and consequently their corrosion protection performance.

OIH materials represent an important part of the $\mathrm{R} \& \mathrm{D}$ activities and technology portfolio in companies such as Bayer, Boeing GE, Honeywell, BASF, AkzoNobel, Sumitomo, ASAHI Kasei, ASAHI Glass, Dow Corning, etc. They are also important in more specialized enterprises (Henkel, Procter \& Gamble, Wacker, Nissan Chemicals, Shin-Etsu, Toppan, Mitsubishi Chemicals, NEPES, Merck, MicroResistTechnologies, etc.). However, the present review is focused mainly on OIHs based on siloxane (i.e., at least one of the precursors used is a siloxane) gels produced by sol-gelderived methods to improve resistance to oxidation/ corrosion or to modify/activate the surface properties of metallic substrates, taken from studies at an academic level in the past few years (2001-2013).

\section{Sol-gel process fundamentals and OIHs classification}

The sol-gel process is a low temperature synthetic route and is generally used as a chemical route to synthesize OIH materials. It is particularly advantageous in the production of coatings as it provides an excellent control of precursor stoichiometry and as there are a large number of precursor reagents with tuned functional groups, a diversity of OIH gels could be produced following the same trends. This process also allows the incorporation of additional components that introduce complementary functions of the material such as UV protection, antifouling, antireflection, moisture resistance, corrosion inhibition, and adhesion protection. Moreover, the sol-gel process enables coating deposition on substrates with a large surface area involving simple and inexpensive equipment.

The definition of sol-gel method itself has undergone some changes over time. There are many authors with significantly different definitions, for example Dislich $^{9}$ considered that the sol-gel procedures are only those that take into account multicomponent oxides which are homogeneous at an atomic level. Under different circumstances, Segal ${ }^{10}$ introduced the sol-gel method as the production of inorganic oxides in the form of colloidal dispersion or in the form of metal alkoxides. Others ${ }^{11}$ considered that the sol-gel process was any chemical process whose starting point was a solution resulting in a solid phase whether or not precipitate (even though the system did not result in a strong network). Given the diversity of definitions found, a broader sol-gel method definition was considered $^{12}$ : "every process that starts from precursor's solutions with intermediate stages including a gel and/ or a sol." To begin the sol-gel process, the chemical compounds known as the precursors (Table 1), must be selected and dissolved in a certain liquid solvent (where necessary) where they will be chemically transformed, forming a sol. Sols are stable suspensions of colloidal particles within a liquid. ${ }^{13,14}$ This first step is a typical chemical transformation aiming at the

Table 1: Chemical name, empirical formula, structure, and common abbreviation of some of the most commonly used precursors for the preparation of coatings by sol-gel method

Chemical name

Methyltrimethoxysilane

Empirical formula

$\mathrm{C}_{4} \mathrm{H}_{12} \mathrm{O}_{3} \mathrm{Si}$

Tetramethylorthosilicate

$\mathrm{C}_{4} \mathrm{H}_{12} \mathrm{O}_{4} \mathrm{Si}$

Vinyltrimethoxysilane
$\mathrm{C}_{5} \mathrm{H}_{12} \mathrm{O}_{3} \mathrm{Si}$

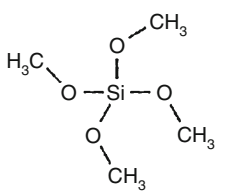

Abbreviation

MTMS

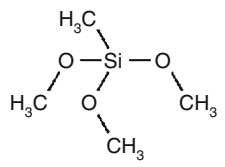

TMOS

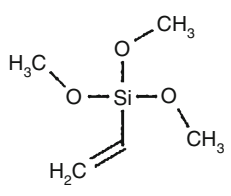


Table 1: Continued

Chemical name

3,3,3-Trifluoropropyltrimethoxysilane

Diethoxydimethylsilane

Triethoxysilane

$\Gamma$-Mercaptopropyltrimethoxysilane

3-Aminopropyltrimethoxysilane

Methyltriethoxysilane

Ethyltriacetoxysilane

Vinyltriethoxysilane

Tetraethoxysilane
Empirical formula

Structure

Abbreviation

$\mathrm{C}_{6} \mathrm{H}_{13} \mathrm{~F}_{3} \mathrm{O}_{3} \mathrm{Si}$

$\prod_{\mathrm{F}}^{\mathrm{F}} \underset{\substack{\mathrm{Si} \\ 1 \\ \mathrm{O}}}{\mathrm{O}-\mathrm{O}-\mathrm{CH}_{3}} \underset{\mathrm{CH}_{3}}{-\mathrm{CH}_{3}}$

$\mathrm{C}_{6} \mathrm{H}_{16} \mathrm{O}_{2} \mathrm{Si}$

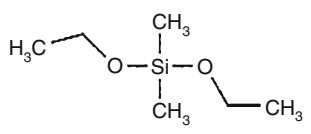

$\mathrm{C}_{6} \mathrm{H}_{16} \mathrm{O}_{3} \mathrm{Si}$<smiles>CCO[SiH](OCC)OCC</smiles>

$\mathrm{C}_{6} \mathrm{H}_{16} \mathrm{O}_{3} \mathrm{SSi}$<smiles>CO[Si](CCCS)(OC)OC</smiles>

$\mathrm{C}_{6} \mathrm{H}_{17} \mathrm{NO}_{3} \mathrm{Si}$<smiles>CO[Si](CCCN)(OC)OC</smiles>

APTMS

$\mathrm{C}_{7} \mathrm{H}_{18} \mathrm{O}_{3} \mathrm{Si}$<smiles>CCO[Si](C)(OCC)OCC</smiles>

MTES

$\mathrm{C}_{8} \mathrm{H}_{14} \mathrm{O}_{6} \mathrm{Si}$<smiles>CC[Si](OC(C)=O)(OC(C)=O)OC(C)=O</smiles>

ETAS<smiles>C=C[Si](OCC)(OCC)OCC</smiles>

VTES<smiles>CCO[Si](CC)(OCC)OCC</smiles> 
Table 1: Continued

Chemical name

Empirical formula

Structure

Abbreviation

$\mathrm{N}$-(2-Aminoethyl) 3-aminopropyl trimethoxysilane

$\mathrm{C}_{8} \mathrm{H}_{22} \mathrm{~N}_{2} \mathrm{O}_{3} \mathrm{Si}$<smiles>CO[Si](CCCNCCN)(OC)OC</smiles>

AEAPS

Bis(trimethoxysilyl)ethane

$\mathrm{C}_{8} \mathrm{H}_{22} \mathrm{O}_{6} \mathrm{Si}_{2}$<smiles>CO[SiH](CC[Si](OC)(OC)OC)OC</smiles>

BTMSE

Phenyltrimethoxysilane

$\mathrm{C}_{9} \mathrm{H}_{14} \mathrm{O}_{3} \mathrm{Si}$

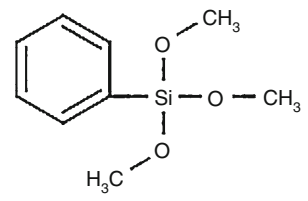

PTMS

3-Glycidoxypropyltrimethoxy-silane

$\mathrm{C}_{9} \mathrm{H}_{20} \mathrm{O}_{5} \mathrm{Si}$<smiles>CO[Si](CCCOCC1CO1)(OC)OC</smiles>

GPTMS

3-Aminopropyltriethoxysilane

$\mathrm{C}_{9} \mathrm{H}_{23} \mathrm{NO}_{3} \mathrm{Si}$<smiles>CCO[Si](CCCN)(OCC)OCC</smiles>

APTES

$\Gamma$-Methacryloxypropyl-trimethoxysilane

$\mathrm{C}_{10} \mathrm{H}_{20} \mathrm{O}_{5} \mathrm{Si}$<smiles>C=C(C)C(=O)OCCC[Si](OC)(OC)OC</smiles>

MAPTS

2-(3,4-Epoxycyclohexyl)-ethyltrimethoxysilane

$\mathrm{C}_{11} \mathrm{H}_{22} \mathrm{O}_{4} \mathrm{Si}$<smiles>CO[Si](CCC1CCC2OC2C1)(OC)OC</smiles>

ECHETS

$\mathrm{C}_{12} \mathrm{H}_{28} \mathrm{O}_{4} \mathrm{Ti}$<smiles></smiles> 
Table 1: Continued

Chemical name

Empirical formula

Structure

Abbreviation

Zirconium(IV) tetra-1-propoxide

$\mathrm{C}_{12} \mathrm{H}_{28} \mathrm{O}_{4} \mathrm{Zr}$<smiles>CC(C)O[Te](OC(C)C)(OC(C)C)OC(C)C</smiles>

ZrTPO

Diethylphosphonatoethyl-triethoxysilane

$\mathrm{C}_{12} \mathrm{H}_{29} \mathrm{O}_{6} \mathrm{Psi}$<smiles>CCO[Si](CCP(=O)(OCC)OCC)(OCC)OCC</smiles>

PHS

Bis-1,2-[triethoxysilyl]-ethane

$\mathrm{C}_{14} \mathrm{H}_{34} \mathrm{O}_{6} \mathrm{Si}_{2}$

2,2-Bis-(4-hydroxyphenyl)-propane

$\mathrm{C}_{15} \mathrm{H}_{16} \mathrm{O}_{2}$<smiles>CCO[Si](CC[Si](OCC)(OCC)OCC)(OCC)OCC</smiles>

BTSE<smiles>CC(C)(c1ccc(O)cc1)c1ccc(O)cc1</smiles>

BPA<smiles>CCO[Si](OCC)(OCC)OCCCN=C=O</smiles>

Bis-[3-(triethoxysilyl)-propyl]-tetrasulfide

$\mathrm{C}_{18} \mathrm{H}_{42} \mathrm{O}_{6} \mathrm{~S}_{4} \mathrm{Si}_{2}$<smiles>CCO[Si](CCCSSSSCCCS(OCC)(OCC)OCC)(OCC)OCC</smiles>

BTSTS

formation of a sol of colloidal particles or a solution of oligomers (small polymers). As sol is a fluid it can be cast in a mold, or be applied on the substrates using various shaping techniques ${ }^{8}$ and can be stored for a certain time before further casting. After this process, a gel is formed and to achieve gelation, the chemical transformations in a sol must be allowed to proceed until a rigid and interconnected network forms, only limited by the walls of the container. ${ }^{11}$ Another important step in the sol-gel art is the drying, which is a very critical one. When drying occurs under normal conditions, it usually results in a contraction of the gelled network. The resulting dry gel, commonly referred as xerogel, can be reduced in volume between five and ten times when compared with the initial wet gel. $^{11,13}$ This phenomenon involves the contraction deformation processes of the network and the transport of liquid through the pores of structure. If the gel 
is dried in wet supercritical conditions, the shrinkage will be minimal, and the resulting product is known as an aerogel. If the smallest dimension of the gel is more than a few millimeters, the material is classified as a monolith and when the gelation occurs by fast evaporation of the solvent, films and fibers will be produced (Fig. 1). However, owing to the loss of volatile byproducts formed in the hydrolysis-condensation reactions, it is difficult to control sample shrinkage during three-dimensional network formation. ${ }^{10,11,13,15-18}$

According to Hench and West ${ }^{14}$ there are three approaches used to produce sol-gel monoliths:

Method 1: Gels obtained from gelation of colloidal solutions;

Method 2: Hydrolysis and polycondensation of alkoxide or nitrate precursors followed by hypercritical drying of gels;

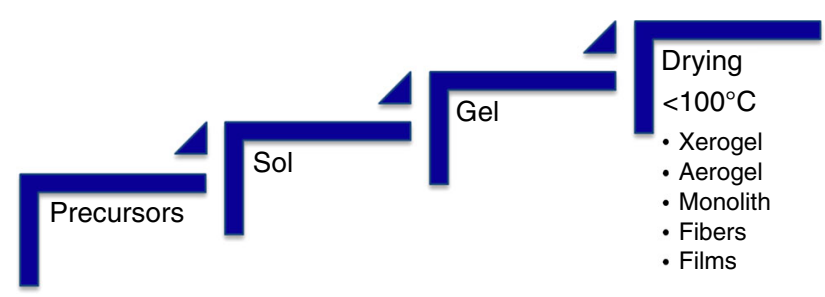

Fig. 1: Main steps to obtain materials by sol-gel processing (temperatures $<100^{\circ} \mathrm{C}$ ) (adapted from Hench and West $^{14}$ )
Method 3: Hydrolysis and polycondensation of alkoxide precursors followed by aging and drying under ambient atmospheres.

Figure 2 shows the different routes of the sol-gel processing and their relation with the three systematic approaches proposed by Hench and West. ${ }^{14}$

The properties of an $\mathrm{OIH}$ gel material are not the simple addition of each individual contribution of its components. It depends on the chemical nature, on the size and morphology, as well as on the synergies established between each component. The diverse composition of these materials has led to specific classifications within OIHs. The influence of the interface is very important so its nature has been used to classify these materials.

In one of the earliest papers, published by Sanchez and Ribot, ${ }^{19}$ OIH networks were divided into two general classes: class I and II. ${ }^{19}$ Later, Wojcik and Klein ${ }^{20}$ introduced a classification of three main classes based on OIH chemical structures. Class I includes the OIHs where the organic and inorganic components interact via hydrogen bonds, Van der Waals forces, or ionic bonds (Fig. 3).

Class II includes OIHs where the inorganic and organic components are connected by covalent bonds (as shown in Fig. 4). The support network is formed by condensation of chemical structural units (called gel precursors) where organic and inorganic components coexist. During the gel process, the addition of the precursor's structure replicates a stable macromolecu-

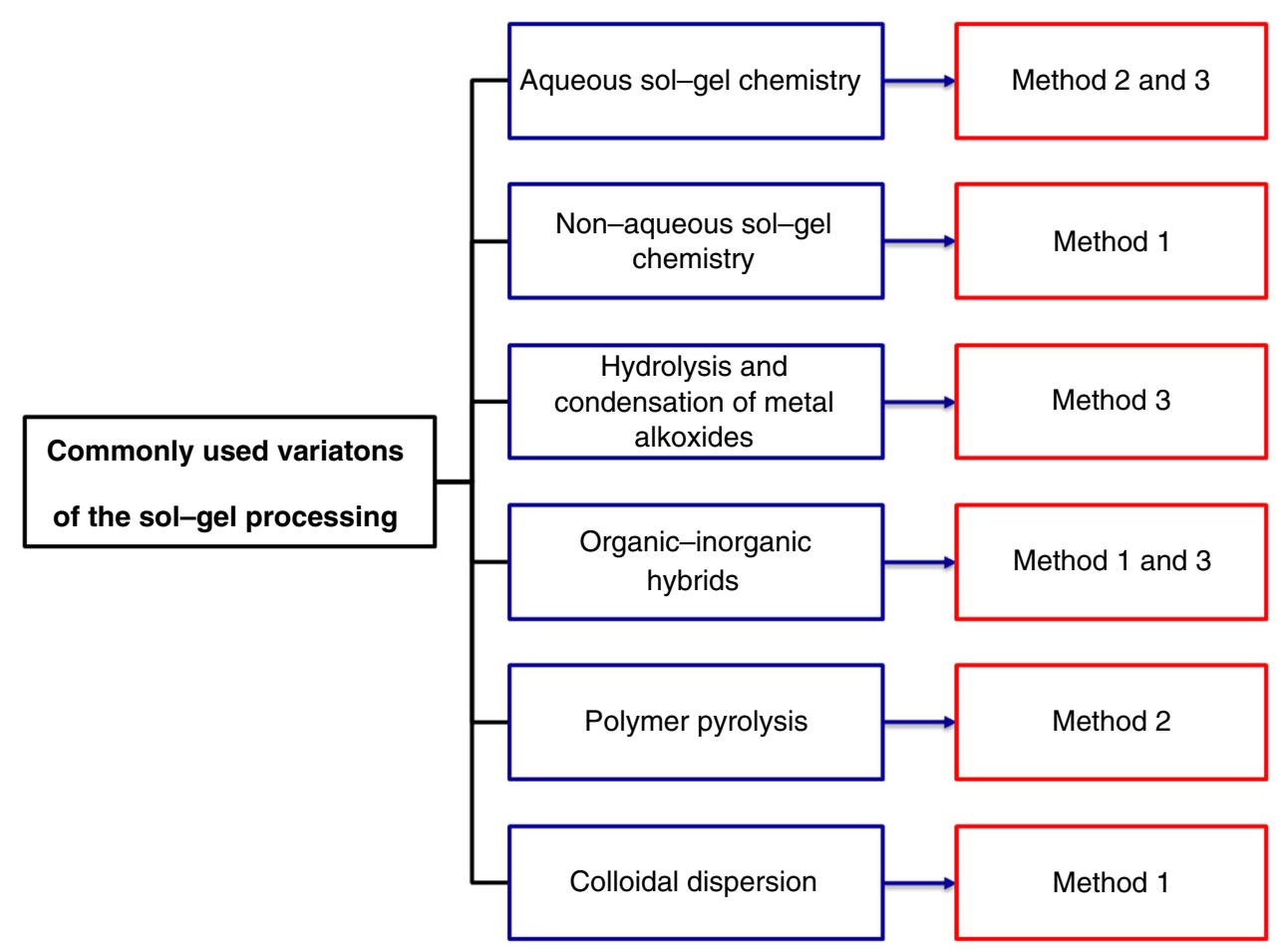

Fig. 2: Different routes of the sol-gel process and their relation with the three systematic approaches proposed by Hench and West ${ }^{14}$ 

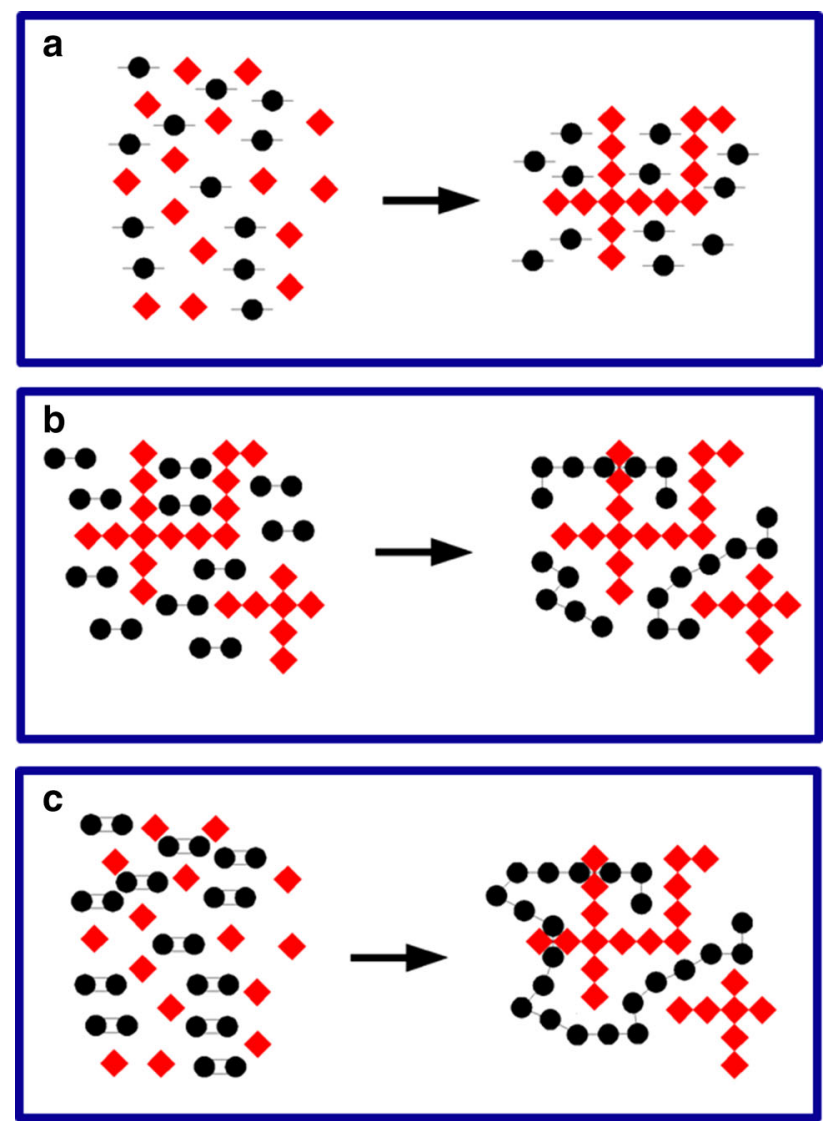

Fig. 3: Interactions established between the organic and inorganic components for OlHs class I. (a) - organic molecules immobilized in an inorganic network - organic molecules embedded in an inorganic network - followed by polymerization forming a semi-interpenetrating network; (c) simultaneous formation of two networks from organic molecules 0 and inorganic precursors forming an interpenetrating network (adapted from Prado et al. ${ }^{21}$ )

lar network where these two basic components are chemically bonded.

The sol-gel synthesis of OIHs class II based on siloxanes can be easily synthesized because $\mathrm{Si}-\mathrm{C}_{\mathrm{sp}}{ }^{3}$ bonds are rather covalent and therefore quite stable toward attack by nucleophilic species such as water, alcohols, and hydroxylated ligands, among others. The precursors of these compounds are organo-substituted silicic acid esters of general formula $\mathrm{R}_{n}^{\prime} \mathrm{Si}(\mathrm{OR})_{4-n}$, bridged precursors of silesquioxanes $\mathrm{X}_{3} \mathrm{Si}-\mathrm{R}^{\prime}-\mathrm{SiX}_{3}$ $(\mathrm{X}=\mathrm{Cl}, \mathrm{Br}, \mathrm{OR})$ in which $\mathrm{R}^{\prime}$ can be any organofunctional group and $n$ is generally 1 or 2. Organic groups $\mathrm{R}^{\prime}$ may bind to an inorganic network with two distinct purposes, namely as network modifiers or as network formers. If $\mathrm{R}^{\prime}$ is a simple nonhydrolyzable group, it will have a network modifying effect. On the other hand, if $\mathrm{R}^{\prime}$ bears any reactive group that can, for instance, polymerize or co-polymerize (e.g., methacryloyl, epoxy, or styryl groups) or undergo hydrolysis-condensation

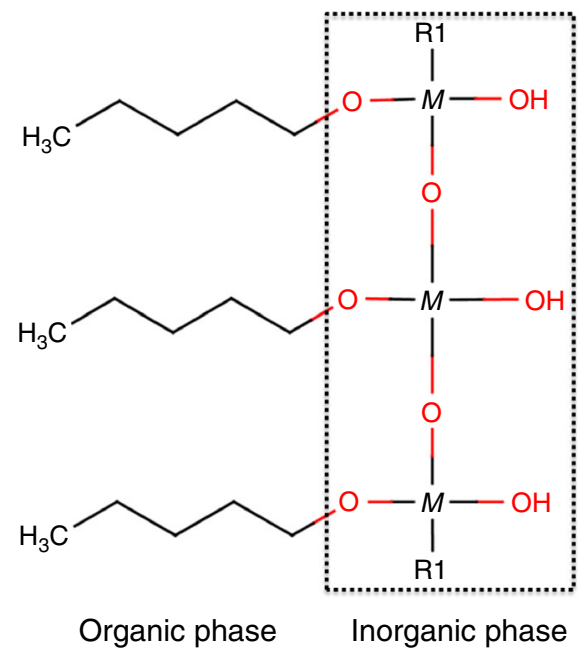

( $M$ represents a network-forming element such as Si, Ti, Zr, $A l, B$, etc. $R 1$ is typically an alkyl group)

Fig. 4: Organic-inorganic interactions for OIHs class II (adapted from Prado et al. ${ }^{21}$ )

(trialkoxysilyl groups), it will act as a network former. ${ }^{16}$

The synthesis of this class of OIHs usually involves polycondensation reactions between di-, tri-, or polyfunctional organosiloxanes and metal alkoxides (e.g., $\mathrm{Si}(\mathrm{OR})_{4}, \mathrm{Ti}(\mathrm{OR})_{4}, \mathrm{Zr}(\mathrm{OR})_{4}$, etc. $)$. Polyfunctional alkoxysilanes and metal alkoxides are effective crosslinkers allowing for the production of OIHs materials with mechanical and thermal properties between those of polymers and glasses. The results of hydrolysis and polycondensation of these precursors are organo-polysiloxanes that have properties such as hydrophobicity, corrosion protection, low dielectric constants, or good scratch resistance. ${ }^{21}$ Due to the chemical and physical properties of the OIHs class II that are suitable to prevent corrosion/oxidation of the metallic substrates these are the main focus of this review.

The synthesis reaction involved usually results from the conjugation of two mechanisms, namely ${ }^{12,13,16}$ : hydrolysis of metal alkoxides (step 1, Fig. 5) to produce hydroxyl groups in the presence of stoichiometric water (generally in the presence of acid or base catalyst) followed by polycondensation of the resulting hydroxyl groups and residual alkoxyl groups to form a three-dimensional network (step 2, Fig. 5).

The first step is the formation of a covalent bond between the organic and inorganic components giving rise to the "seed" precursor molecule. The conversion of the precursors into $\mathrm{OIH}$ materials proceeds via the formation of siloxane ( $\mathrm{Si}-\mathrm{O}-\mathrm{Si})$ bonds. This process takes place by hydrolyzing monomeric tetrafunctional alkoxide precursors employing a mineral acid (e.g., $\mathrm{HCl}$ ) or base (e.g., $\mathrm{NH}_{3}$ ) as a catalyst.

Figure 6 shows a schematic of a practical example including the generic steps in the preparation of a particular example of class II OIH material involving 


\section{Step 1: Hydrolysis reaction}

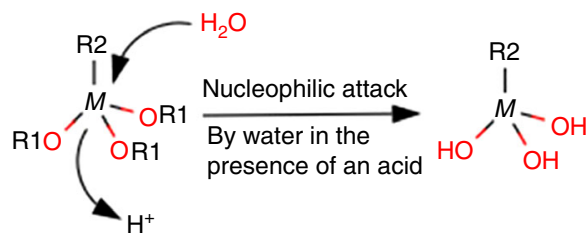

( $M$ represents a network-forming element such as Si, Ti, Zr, Al, B, etc. $R_{1}$ and $R_{2}$ are typically an alkyl group)

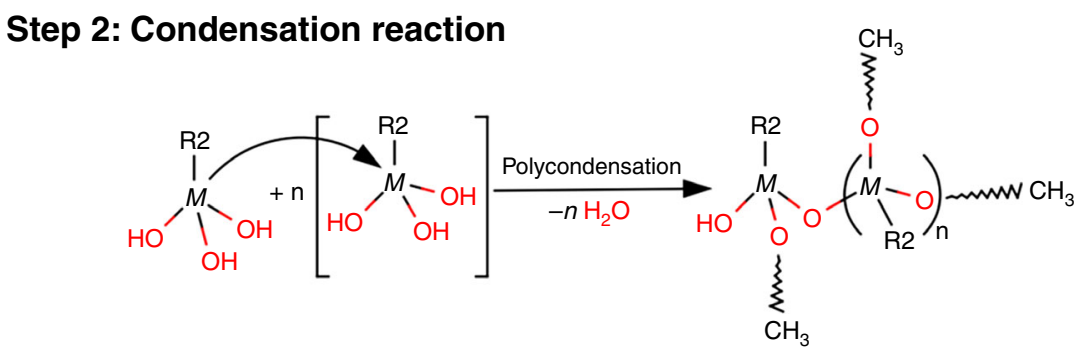

Fig. 5: Generic reactions involved in the preparation of OIH materials through sol-gel method (adapted from Brinker and Scherer ${ }^{11}$ )

the incorporation of a polyether oligomer within the gel matrix. ${ }^{22}$

Class III (Fig. 7) includes OIHs that are based on the combination of both types of interactions assigned to classes I and II. An example of this kind of hybrid is the material obtained by an organic polymer containing hydrolyzable alkoxylanes (SiOR) ${ }_{3}$ and hydrogen acceptor groups such as carbonyls, amines, and imides. $^{21}$

\section{Sol-gel coatings for metals}

Corrosion protection of metallic substrates has long been one of the key roles performed by organic coatings, one of the most cost-effective means of providing practical protection from corrosion to easily corrodible metallic structures and items. The production of eco-friendly sol-gel coatings to prevent corrosion on metallic substrates was one of the emerging areas of application, competing with conventional chromate and phosphate CCCs.

Corrosion protective coatings are not just a barrier layer between the object and its environment. They should act to: protect small and local areas of exposed substrate and stop the spread of damage; limit the passage of current on the substrate; slow/inhibit oxygen (and other oxidants') mobility toward the metal surface; minimize water and electrolyte penetration and release embedded inhibitor species that contribute to substrate passivation or block corrosion reactions. $^{23-28}$ Coating application or further removal processes should be performed with hazard-free procedures and environmentally friendly reagents as well as by producing eco-friendly residues. ${ }^{29}$ The use of sol-gel method to produce coatings for corrosion protection fulfills the main requirements of what should be an environmentally friendly process. It is a waste-free method, excludes any washing stage, and is able to produce coatings with high specific pore volume, specific surface areas, and high purity. Due to low temperature synthesis (frequently close to room temperature), the thermal volatilization and degradation of entrapped species (such as organic inhibitors) is minimized. As liquid precursors are used in the synthesis, it is therefore possible to cast coatings in complex shapes and produce thin films without the need for machining or melting.

Processing of sol-gel-derived film coatings and their applications has been extensively reviewed before $2001^{4,30}$ Metroke et al. ${ }^{5}$ reviewed the recent advances in the use of sol-gel-derived coatings for improved corrosion resistance of aluminum and steel metal surfaces. Later, in 2005, the pioneering work of van Ooij et al. ${ }^{6}$ demonstrated the applications of functionalized trialkoxysilanes to produce OIH gels, as a prospect for solving the problems of the metal finishing industry. $^{31}$ The traditional metal plating process in this industry involves, for instance, the use of CCC, lead, cadmium, and cyanide in plating baths. These authors have shown that distinct terminal organic groups of the functionalized siloxanes have a key role in the improvement of coating adhesion while the continuous inorganic network formed, largely silicate, provides the coating's mechanical strength and hydrophobicity, ${ }^{6}$ minimizing/avoiding the hazards associated with tradi- 
<smiles>CO[Si](CCCOCC1[CH+]C1)(OC)OCC(C)OC(C)(C)C(C)OC(C)(C)C(C)N</smiles><smiles>CO[Si](CCCOCC(O)CNC(C)C(C)(C)OC(C)C(C)(C)OCCC(C)N(CC(C)C)CC(O)COCCC[Si](OC)(OC)OC)(OC)OC</smiles>

Organic-inorganic precursor

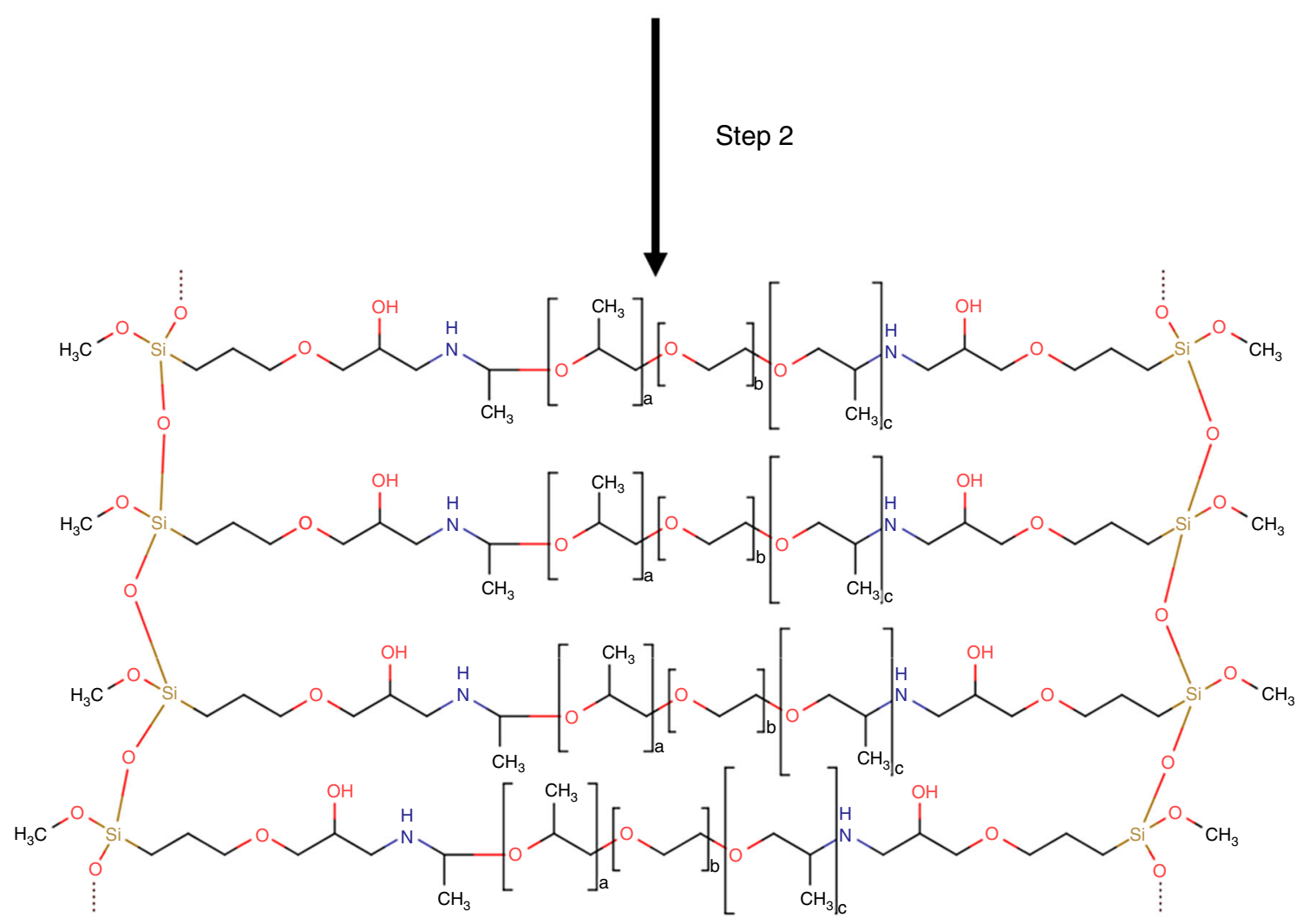

OIH network (amine-alcohol-silicate)

Fig. 6: Practical example of the generic steps involved in the preparation of OIH materials ${ }^{22}$

tional metal plating baths especially when it comes to heavy metals and cyanide.

In 2002, Gray and Luan ${ }^{7}$ reviewed some the most relevant processes applied to the protection of magnesium alloys, namely electrochemical plating, conversion films, anodizing, gas-phase deposition, and laser surface alloying/cladding. ${ }^{7}$ Since then, the research and progress on $\mathrm{Mg}$ alloys have improved rapidly across the world, as highlighted in the paper published by $\mathrm{Wu}$ and Zhang ${ }^{32}$ where a detailed review is given about the state of the art methods of corrosion protection as well the patents regarding the 


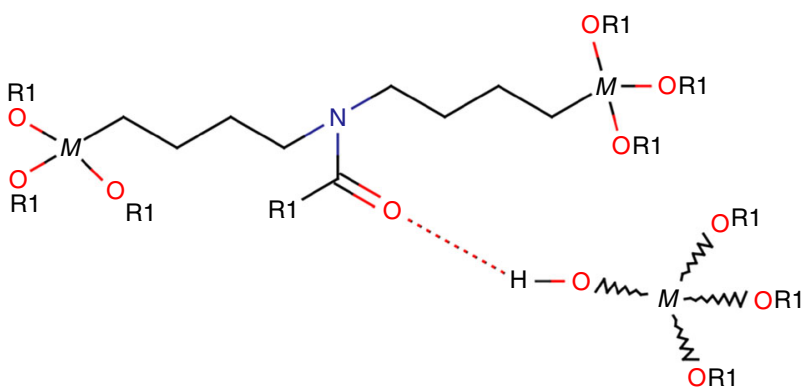

( $M$ represents a network-forming element such as Si, Ti, Zr, Al, B, etc. $R_{1}$ is typically an alkyl group)

Fig. 7: Organic-inorganic interactions for OlHs class III (adapted from Prado et al. ${ }^{21}$ )

protection of magnesium alloys. ${ }^{32}$ The authors found that although magnesium alloy-related patents exhibited a steady increase in the last 20 years, only a small amount was applied in industries. ${ }^{10}$ In 2012, Hu et al. reviewed the progress in corrosion protection of magnesium alloys. The authors focused on the several types of existing coatings and on the techniques used to evaluate the corrosion performance of those coatings. ${ }^{33}$

\section{Organic-inorganic hybrid (OIH) sol-gel coatings for corrosion protection}

Organic-inorganic hybrid materials are the new generation of multifunctional materials with a broad spectrum of useful properties and diverse applications. The combination of inorganic with organic and/or bioactive components in a single material has led to many interdisciplinary scientific advances which can be seen in a large number of publications. Searches in Science Direct, Springerlink, ECS Digital Library, and ACS Publications, including the keywords "hybrid" and "sol-gel," returned approximately 21,000 scientific articles that were published since 1990. A bar chart of the number of identified scientific publications (Fig. 8) shows that the number of publications in 2013 is about forty-five times the number of those published in 1990.

In the last few decades, the growing interest in developing new materials has led to the preparation of several organically modified silicates as potential metal corrosion coating materials.

Many material scientists and chemists, such as Schmidt $^{34}$ and Wilkes, ${ }^{35}$ started to synthesize OIH materials by sol-gel processes and published a series of pioneering research articles. Since then, a diversified number of sol-gel-based protective coatings have been produced and tested. In the last few decades, the use of pretreatments based on siloxanes has been widespread due to their properties, namely the low cost and low environmental impact. Several studies have been carried out extensively since the early $1990 \mathrm{~s}^{6,8,36,37}$ and it has been demonstrated that siloxanes can be effective in protecting metallic substrates against corrosion (i.e., steel, aluminum alloys, zinc alloys, copper,

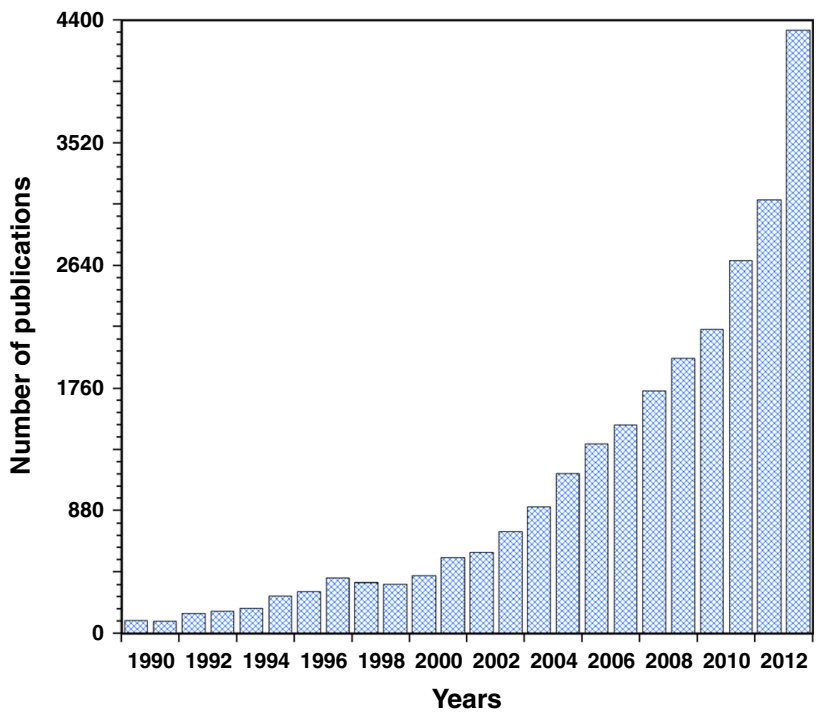

Fig. 8: Bar chart of scientific publications published from 1990 until 2013 found in Science Direct, Springerlink, ECS Digital Library, and ACS Publications using the key words "organic-inorganic hybrids"

and magnesium alloys). However, the need for tuned materials for specific purposes has led toward the production and development of new OIH gel materials which combine both the advantages of organic polymers (flexibility, lightweight, good impact resistance) and the features of inorganic material components (processability, high mechanical strength, excellent chemical resistance, and thermal stability).

Particular types of OIH materials have also been named, either as ORMOSILs (acronym generated from ORganically MOdified SILicates) or OMOCERs (from ORganically MOdified CERamics) depending on the precursors used (Table 1) and synthesis method.

The most effective approach in the production of OIH materials seems to be the sol-gel technique with its specific ability to create a spacious network (macromolecular network) containing $\mathrm{M}-\mathrm{O}$ bonds under mild (room temperature) synthesis conditions either with or without a solvent. ${ }^{21,38}$ Their properties are highly dependent on the degree of mutual phase dispersion (therefore dependent on the organic/inorganic ratio), the reactivity of crosslinking alkoxide reagents, the processing steps, and the solvents. ${ }^{39}$ The presence of polymeric chains within the OIH matrix contributes to the material's high electrical resistivity and impermeability, providing similar properties to the usual painting materials.

The hybrid structure maximizes the preparation of materials that could lead to efficient coatings against corrosion as well as ensuring primary technological needs. ${ }^{40}$

Over time, several review papers have been periodically published about OIH gels, giving an up-to-date description of state of the art contributions. The most important reviews published since 2000 are listed chronologically in Table 2. 
Table 2: The main review articles about sol-gel processes since 2000

\begin{tabular}{|c|c|c|}
\hline Year & Authors & Discussed subject matter \\
\hline 2000 & $\begin{array}{l}\text { Bescher and } \\
\text { Mackenzie }\end{array}$ & Review of the physical properties of sol-gel coatings \\
\hline 2002 & Attia et al. ${ }^{42}$ & Overview of sol-gel-derived coatings, namely the processes and optical applications \\
\hline \multirow[t]{2}{*}{2007} & $\begin{array}{l}\text { Mackenzie and } \\
\text { Bescher }^{43}\end{array}$ & $\begin{array}{l}\text { Usefulness of the sol-gel process in the synthesis of materials comprising nanoscale } \\
\text { architectures. Description of the processing of semiconducting, metallic, ferroelectric, or } \\
\text { scintillating nanoparticles in various oxide matrices }\end{array}$ \\
\hline & Niederberger ${ }^{44}$ & Review of nonaqueous sol-gel routes to produce metal oxide nanoparticles \\
\hline \multirow[t]{2}{*}{2008} & Sakka ${ }^{45}$ & $\begin{array}{l}\text { Review of the effects of the starting solution composition on the reaction in alkoxysilane solutions } \\
\text { for the formation of bulk and fibrous materials, and the microstructure of a particular film coating }\end{array}$ \\
\hline & Dimitriev et al. ${ }^{46}$ & Summary of the most significant research achievements in sol-gel science and technology \\
\hline \multirow[t]{3}{*}{2009} & Kozhukharov ${ }^{47}$ & $\begin{array}{l}\text { Discussion of basic concepts related to sol-gel technologies, as well as the most important } \\
\text { problems. Correlation of the properties of obtained products, synthesis conditions and the } \\
\text { features of the methods applied }\end{array}$ \\
\hline & $\begin{array}{l}\text { Wang and } \\
\text { Bierwagen }^{38}\end{array}$ & $\begin{array}{l}\text { Introduction of the basic chemistry involved in sol-gel processes, the progress and development } \\
\text { of sol-gel protective coatings on metal substrates and alloys until 2007. Summary of the most } \\
\text { relevant limitations of sol-gel coatings }\end{array}$ \\
\hline & Benvenutti et al. ${ }^{48}$ & $\begin{array}{l}\text { Discussion of the properties and characteristics of hybrid materials related to experimental } \\
\text { synthesis conditions }\end{array}$ \\
\hline \multirow[t]{2}{*}{2011} & $\begin{array}{l}\text { Pandey and } \\
\text { Mishra }^{49}\end{array}$ & $\begin{array}{l}\text { Description of synthesis routes to produce hybrid composite materials derived by combining the } \\
\text { sol-gel approach and organic polymers }\end{array}$ \\
\hline & Sanchez et al. ${ }^{15}$ & Discussion of the major applications of $\mathrm{OIH}$ (biological based) materials \\
\hline 2012 & $\begin{array}{l}\text { Balgude and } \\
\text { Sabnis } 50\end{array}$ & $\begin{array}{l}\text { Description of potential of sol-gel-derived hybrid coatings processes for the production of } \\
\text { multifunctional pretreatments for metallic substrates }\end{array}$ \\
\hline \multirow[t]{2}{*}{2013} & $\begin{array}{l}\text { Abdolah Zadeh } \\
\text { et al. }{ }^{51}\end{array}$ & Discussion of the most relevant existing works on self-healing sol-gel coatings \\
\hline & $\begin{array}{l}\text { Chaturvedi and } \\
\text { Dave }\end{array}$ & $\begin{array}{l}\text { Discussion of the methods to design nanomaterials where emphasis was given to the sol-gel } \\
\text { method }\end{array}$ \\
\hline
\end{tabular}

In the nineties, ${ }^{53}$ the $\mathrm{OIH}$ concept firmly emerged and an increased number of papers focusing on this area were published within a short period of time. In 2001, several important review papers on this subject were published. Schottner ${ }^{54}$ and Walcarius ${ }^{55}$ reviewed the perspectives of the hybrid sol-gel-derived polymers and reported the applications of OIH materials in the various fields of electrochemistry. Mitzi ${ }^{56}$ selected examples of $\mathrm{OIH}$ films and discussed the techniques used on the deposition of OIH sol-gel materials.

Several authors focused review papers on aspects related with gel synthesis processes, like Hay and $\mathrm{Raval}^{57}$ who reported on the use of the nonhydrolytic sol-gel route to synthesize OIHs. Arkhireeva et al. ${ }^{58}$ synthesized in 2004 OIHs using both the hydrolytic and nonhydrolytic sol-gel routes. The authors showed that both routes produced OIHs. However, an improved control of the shape and particle size was obtained using the hydrolytic process. In the same year, Castelvetro et al. ${ }^{40}$ reviewed and discussed the synthetic approaches to produce nanostructured $\mathrm{OIH}$ materials. The main focus was on processes and products that can be carried out in an aqueous medium, even though nonaqueous systems have also been discussed. Later in 2005, Sanchez et al. ${ }^{59}$ summarized the general chemical pathways to prepare
OIH materials and presented remarkable examples of applications of functional OIHs in several areas. The authors highlighted the use of protective coatings based on phenylsilsesquioxanes on structures for naval aircrafts and silsesquioxane-polyester mixtures in coil coating applications. The use of an OIH multilayer system on a mosaic panel of the 14th century "Last Judgment Mosaic" can be seen in the St. Vitus cathedral in Prague. The OIH multilayer system, highlighted by the authors, is composed by a functional layer of organo-alkoxysilanes and oxide nanoparticles, placed between the substrate and a fluoropolymer coating. 59

The intense research efforts on this particular area have justified, almost yearly, a detailed review paper reporting state-of-art OIHs. The fundamental review papers were written by Innocenzi et al., ${ }^{60}$ Dash et al., ${ }^{61}$ Lebedev, ${ }^{62}$ and Sanchez et al. ${ }^{63}$

Multilayer systems combining different sol-gel layers with different functions are also an area with high potential and have started to be exploited. The first detailed used of OIHs was a bilayer system to prevent corrosion of metallic substrates by the combination of a super-hydrophobic OIH coating and an OIH coating doped with corrosion inhibitors, proposed by Zheng and $\mathrm{Li}^{64}$ in 2010. 


\section{OIH coatings for corrosion protection of iron-based alloys}

Steel is the most common and versatile metal currently applied and can be classified either as carbon steel (CS) or steel alloy (SA). SA materials cover an extensive range of steels including low-SAs, stainless steel (SS), heat-resistant steels, and tool steels. ${ }^{65}$ SS can be produced with a wide range of properties and can be used in many different industrial fields, owing to their mechanical and corrosion properties. ${ }^{65}$ Steel surface substrates are traditionally passivated by the use of conversion coatings, phosphating, and chromating. These treatments produce a layer of corrosion products - the passivation layer-capable of resisting furthering chemical attack. However, due to the high toxicity associated with the use of chromates, several efforts are being made all over the world to find environmentally friendly treatments. OIHs obtained through sol-gel method are potential candidates as the presence of the metal oxides, on the treated steel surfaces, allows covalent bonding between the inorganic parts of the OIHs based on siloxanes ( $\mathrm{Si}-\mathrm{O}-$ metal oxide), as shown in Fig. 9, and making them suitable alternatives to the conventional conversion coatings.

The corrosion resistance behavior of sol-gel coatings or thin films deposited onto these particular metallic substrates has been extensively studied. The studies performed were mainly aimed at testing the capability of sol-gel coatings to improve oxidation and corrosion resistance of the substrate.

The most relevant information and conclusions gathered from the analyzed papers about the use of OIH gels based on siloxane (i.e., at least one of the precursors used is based on siloxanes) coatings are summarized in Table 3, which is organized according to date of publication. By analyzing the content of the collected bibliography, it was concluded that the study of alternative precursors for the production of new OIH materials, using sol-gel technology seems to have slightly evolved when compared with the amount of precursors available in the market.

Considering all the data gathered in Table 3 and Fig. 10, it is shown that only $13 \%$ of the OIH (class II) based on siloxanes were produced without the precursors TEOS, GPTMS, MAPTS, MTES, and MMA. It is also shown that TEOS is used in the majority of the publications found for these substrates. Although the number of publications has increased significantly over the past 4 years, the research for this type of substrates is still confined to a few precursors and this is especially notable when compared to studies published before 2008. This unusual behavior may be due to the search for the OIH coating with the optimum performance since the sol-gel method allows, with simple changes in the synthesis parameters, to obtain $\mathrm{OIH}$ materials with very distinct properties. The corrosion protection properties of OIH coatings are strongly dependent on
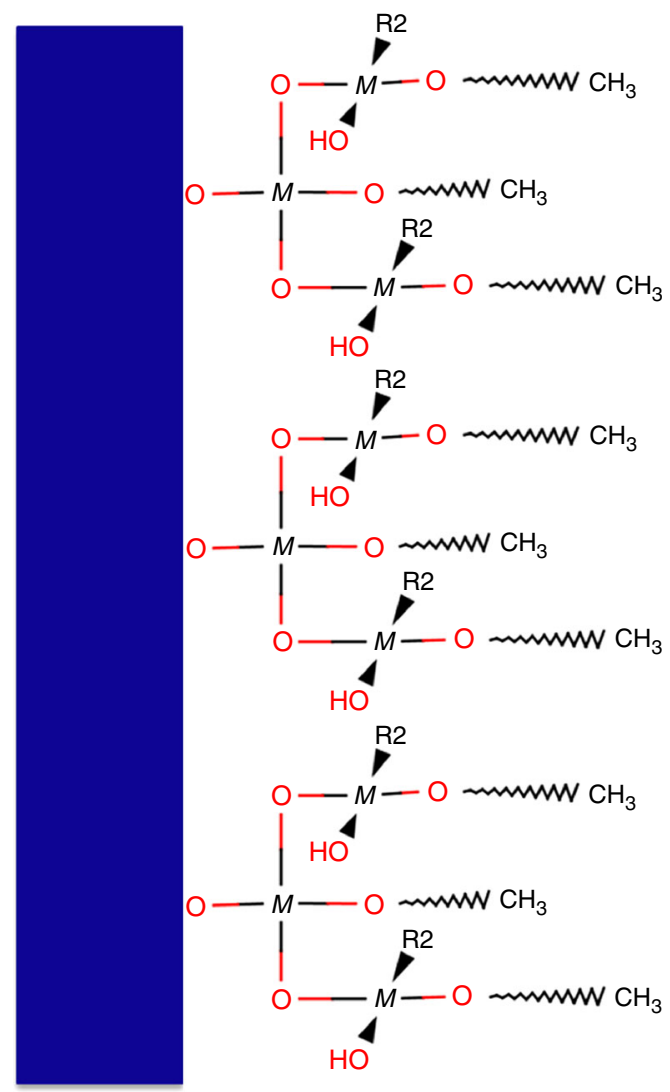

Mettallic substrate

$\mathrm{OIH}$

( $M$ represents a network-forming element such as Si, Ti, Zr, Al, B, etc. $R_{2}$ is typically an alkyl group)

Fig. 9: Schematic representation of the interactions between OIHs class II and the metallic substrate (adapted from Prado et al. ${ }^{21}$ )

their processing conditions, such as aging, reaction $\mathrm{pH}$, curing temperature, and molar ratio of precursors. The statistic data referred to above suggests that the research efforts were more focused in optimizing the synthesis process instead of testing and studying new precursors.

The publications found focused mostly on the use of TEOS, GPTMS, MAPTS, and MTES including, in some cases, the performance of coating materials with embedded corrosion inhibitor species. Generally, the reported studies showed that those OIH coatings exhibit a promising performance in protecting the CS and iron-based alloys against corrosion. However, a comparative study between the properties of the $\mathrm{OIH}$ coatings obtained by each author was not possible since the methods and conditions used to evaluate the OIH coatings performance were not the same and the results themselves were not comparable. 
Table 3: Studies on corrosion protection using OIH (class II) sol-gel coatings on carbon, steel alloys, and SS substrates (2001-2013)

Year Precursors

Results and conclusions

References

2001 TEOS, MAPTS

2002 DGEBA, APTMS

2003 TEOS, MAPTS

GPTMS, AEAPS, APTES, MAPTS

2004 TEOS, MTES

MTES, TIPMS, TIBMS

2005 TEOS, MTES

TEOS, MTES

2006 GPTMS, TEOS

TEOS, MAPTS $\left(\mathrm{SiO}_{2}\right.$ gel/Dacromet)

TEOS, MTES

2008 TEOS, MTES, GPTMS

TEOS, MTES, $\mathrm{AICl}_{3} .6 \mathrm{H}_{2} \mathrm{O}$,

2009 TEOS, MTES

Silicone-epoxide resin (Silikopon EF)

TEOS, MAPTS, MMA

2010 TEOS, MAPTS

TEOS, MAPTS

TEOS, MAPTS

TEOS, MAPTS, MMA

GPTMS, ZrTPO

MAEP, MAPTS

2011 TIPT, PAPTES

2012 TEOS, VTES

TEOS, LDF

TEOS, MTES

GPTMS, TIPT

TEOS, MAPTS, MMA

GPTMS, $\mathrm{Al}\left(\mathrm{O}^{\mathrm{S}} \mathrm{Bu}\right)_{3}$

TEOS, MAPTES

TEOS, MAPTS, MMA

OIH coating enhanced corrosion protection, excellent film adhesion,

66 and flexibility

OlH coatings studied offered corrosion protection

Uniform and defect-free coatings that enhanced corrosion protection

Efficient coatings in protecting surfaces from external influences

$\mathrm{OIH}$ coatings showed high stability and resistance to pitting in simulated body fluids

OlH coatings were thermally stable and the refractive index decreased with organic groups

Homogeneous and crack-free OIH coatings exhibited enhanced corrosion resistance

OlH coating adherence on the substrate surface was good and corrosion resistance of bare material improved

Passivation of the substrate was enhanced

Precursors produced a crack-free surface and enhanced the erosion-corrosion resistance of Dacromet

Crack-free and continuous coatings. Effective barrier against corrosive environments

OlH coatings exhibited good anticorrosion properties provided good corrosion resistance

OIH coatings effectively protected the surface of the substrate against corrosion

OIH coating provided good corrosion resistance for substrates against alkaline, acidic, and saline conditions

OIH coating provided good corrosion resistance at OCP conditions

Best corrosion resistance for OIH coatings obtained with TEOS/ MAPTS molar ratio $=2$

$\mathrm{OlH}$ coatings increased the hydrophilic properties of the substrate surface and significantly improved the corrosion resistance in physiological media

OlH coatings with defect-free, smooth surface, and good substrate adhesion improved corrosion resistance

$\mathrm{OlH}$ film improved the barrier effect against corrosion

Coatings increased the corrosion resistance of substrate

Coating improved corrosion resistance when compared with the uncoated samples

Coatings were dense, uniform, defect-free and provide protection to 88 the substrate against corrosion

$\mathrm{OIH}$ coatings showed to be a promising drug delivery system that can be applied to metallic implants

OlH produced showed a barrier action against different corrosive media

OIH films including 10 and $50 \mathrm{~nm}$ silica nanoparticles were produced and exhibited low corrosion current density

Silane-titania hybrid coating with inhibitor-loaded nanocontainers showed the best performance

OlH coatings prepared protected the substrate against corrosion 93

Influence of cerium concentration on behavior against corrosion of the OIH coating was studied

Barrier properties of the OIH coating were improved by the incorporation of inorganic fillers

Anticorrosion properties of the OIH improved when the MAPTS was 96 added to the formulations 
Table 3: Continued

n-PTMS, TEOS

TEOS, MTES, PTMS

GPTMS, BPA

TEOS, ZrTPO

2013 TEOS, MAPTS

TEOS, MAPTS, MMA

GPTMS, $\mathrm{Al}\left(\mathrm{O}^{\mathrm{s}} \mathrm{Bu}\right)_{3}$

GPTMS, MTMS

GPTMS, OTES, ZrBTO

TEOS, MPTMS

GPTMS, TEOS

GPTMS, TEOS

TEOS, MTES

ER, APTES
Both pure $\mathrm{OIH}$ and copper oxide-OIH coatings improved the corrosion resistance of the substrate

OlH coatings derived from methyl-substituted organically modified silane exhibited superior barrier properties

Cerium-doped OIH coatings protected the substrate effectively

Corrosion behavior of the substrate was enhanced

Addition of polyethyleneglycol within the $\mathrm{OIH}$ allowed improving the barrier effect and the corrosion behavior of the coating

Smooth, crack-free, adherent OIH coatings containing carbon nanotubes protected the substrate against corrosion

Correlation of the influence of temperature on the chemical and structural transformation of the xerogel with the mechanical properties

OlH coatings had excellent substrate adhesion and improved corrosion behavior

$\mathrm{OIH}$ coatings were produced and prevented the oxidation of the substrate

OlH coating synthesized with $\mathrm{Ce}\left(\mathrm{NO}_{3}\right)_{3}$ as catalyst showed improved corrosion behavior of the substrate

Thermally cured cashew nut shell liquid-based $\mathrm{OlH}$ coatings were developed and increased corrosion resistance properties

Corrosion resistance of the OIH films was improved when a phosphoric acid pretreatment was done

OIH coatings enhanced the corrosion resistance of samples

OlH coatings studied showed good corrosion resistance performance in neutral and acidic environments

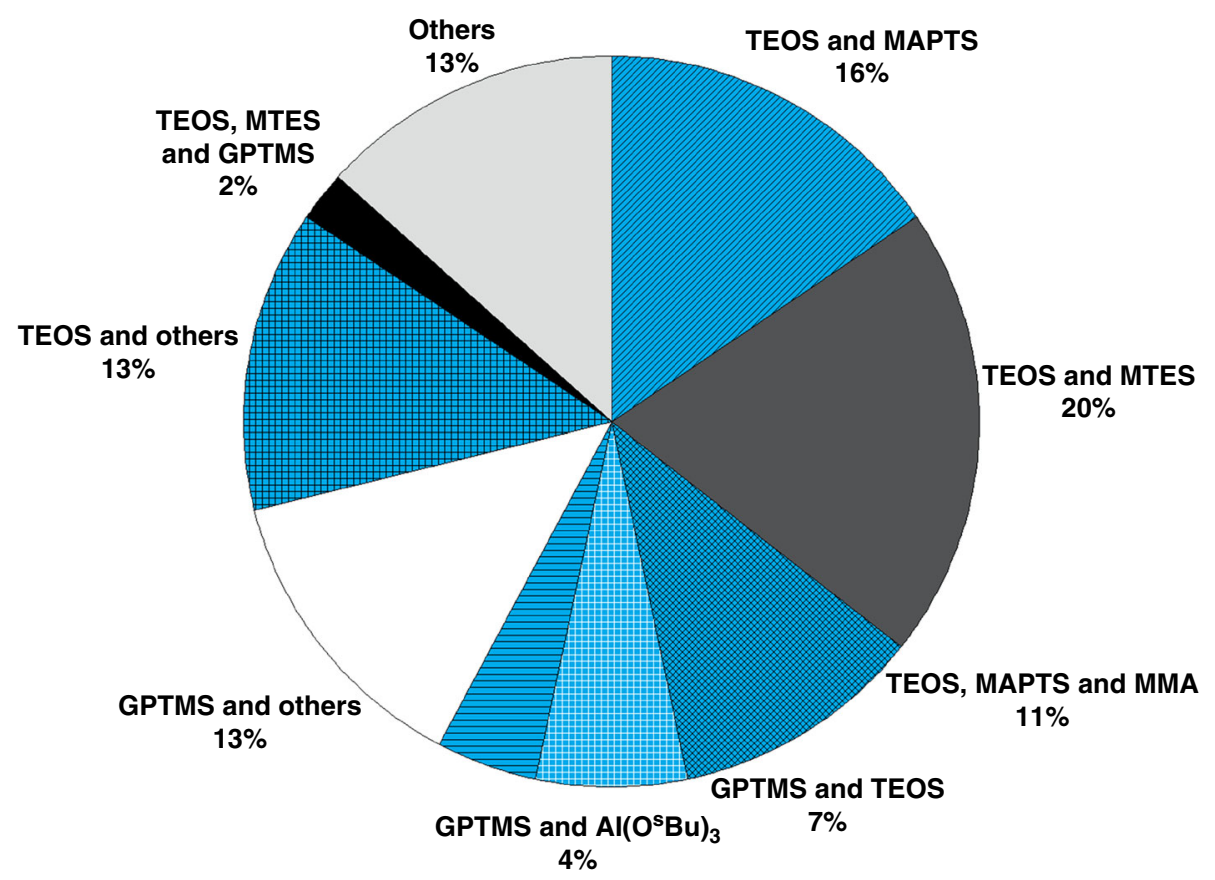

Fig. 10: Distribution of publications according to the type of precursors used for the production of OIH (class II) gel coatings based on siloxanes (i.e., at least one of the precursors used is based on siloxanes) for carbon steel and iron-based alloys (2001-2013) 
The extensive use of TEOS may be due to the fact that this precursor was studied in detail and its properties and reactivity are quite well known at different $\mathrm{pH}$ and temperatures ${ }^{11,111}$ Furthermore, it is less toxic when compared to TMOS, ${ }^{112}$ it is available with a higher purity grade at a relatively low price and has a relatively slow and controllable rate of reaction. ${ }^{49}$ OIHs based on TEOS can produce, at low temperatures, homogeneous films on large areas of substrates $^{113}$ and its addition improves the transparency of the OIH materials. ${ }^{112,114}$ Moreover, OIHs based on TEOS are low cost as this reagent is about four times cheaper than GPTMS and half of the price of MTES, for similar purity grades.

\section{OIH coatings for corrosion protection of aluminum-based alloys}

Aluminum-based alloys are a group of materials with a wide range of applications due to their physical and processability properties, namely low density, easy shaping (in rolling, drawing and extrusion), high corrosion resistance in different environments, easy machining, colorless and nontoxic corrosion products, and high thermal and electrical conductivity together with low aluminum cost, less than 2000 USD/ton. Those characteristics make aluminum-based alloys of remarkable economical and industrial importance. ${ }^{38,65}$

Examples of applications using aluminum-based alloys include building structures, panels, machined components, electro-mechanical components, vehicles and accessories, tools, machine making, shipbuilding, packing, architecture, etc. Aluminum alloys are chosen in these applications due to their natural tendency to form a passivation $\mathrm{Al}_{2} \mathrm{O}_{3}$ layer, which can also be artificially generated by anodizing the substrate. Nevertheless, this passivation layer deteriorates when in contact with aggressive media, such as those containing chloride ions (particularly seaside environments) resulting in pitting corrosion. ${ }^{38}$ To overcome this drawback CCC treatments are usually used due to their effectiveness in corrosion protection of these alloys. However, as stated before, conversion layers based on $\mathrm{Cr}(\mathrm{VI})$ should be avoided and substituted with coatings environmentally friendly. OIH class II sol-gel coatings are potential candidates because, in addition to the OIHs coating properties, these materials can provide a stable Si-O-Al (Fig. 9) bonding between the inorganic functionality of these materials and the formed passivation layer $\left(\mathrm{Al}_{2} \mathrm{O}_{3}\right) .{ }^{115}$

Table 4 gathers the information collected from the published papers where OIH class II sol-gel coatings

Table 4: Studies on corrosion protection using OIH (class II) sol-gel coatings on aluminum-based alloys substrates (2001-2013)

Year

Precursors

Results and conclusions

References

2001 GPTMS, TEOS

GPTMS, TMOS

Comparative studies showed that $\mathrm{OlH}$ film provided better corrosion

116 protection than the CCCs

Incorporation of cerium into sols appears promising for protection against substrate corrosion

2002 GPTMS, TEOS

Curing agents were studied. The amine curing agent produced films with good corrosion resistance

GPTMS, TMOS

Nature of the curing agent significantly influences film structure and the corrosion resistance properties of the $\mathrm{OIH}$ film (curing agents studied: $\mathrm{CF}_{3} \mathrm{SO}_{3} \mathrm{H}, \mathrm{HPF}_{6}$, DETA, TETA, TEPA)

2003 GPTMS, TMOS

Thin and dense protective surface $\mathrm{OlH}$ coatings doped with corrosion inhibitors improved corrosion protection

GPTMS, TEOS, MTES

Addition of particles to OIH coatings notably improved the final corrosion protection properties

GPTMS, AEAPS, APTES, MAPTS

GPTMS, TMOS

$\mathrm{OIH}$ polymers were efficient in protecting surfaces from external influences

Investigation and characterization of the SNAP coating process

Modification of produced thin OIH films with various concentrations of alkyl-modified silanes was found to enhance the corrosion resistance DMTMS, n-PTMS, BTMS, IBTMS, HTMS, IOTMS, OTMS properties of the films on substrates. Hexyl-modified silanes exhibited the highest pore resistance and contact angle values

TEOS, VTMS, MAPTS

Corrosion resistance characteristics depended on the nature and concentration of diluent used. The choice of solvent enables tailoring of the OlH coating structure

MTES, TIPMS, TIBMS

Films were thermally stable, remaining without cracks on the substrates after heat treatment at $800^{\circ} \mathrm{C}$

120 
Table 4: Continued

Year

Precursors

Results and conclusions

References

2005 GPTMS, TMOS, BPA

$\mathrm{OIH}$ coatings were uniform, defect-free, relatively dense, presenting

GPTMS, BPA good adhesion and improved corrosion protection

Coatings obtained improved corrosion protection by forming an

GPTMS, TMOS

impenetrable barrier to water and corrosive agents

GPTMS, TEOS, VTMS, MAPTS

Superior adhesion and corrosion protection make SNAP surface modification a promising alternative

GPTMS, TMOS

$\mathrm{OIH}$ coatings efficiently inhibited the corrosion of the substrate

Inclusion of corrosion inhibitors within the coating has a pronounced effect on reducing a corrosion attack on the substrate

GPTMS, TEOS, ZrTPO

OIH coatings with incorporated zirconium oxide nanoparticles doped with a cerium inhibitor provided long-term corrosion protection

GPTMS, ZrTPO

$\mathrm{OlH}$ sol-gel systems showed potential for aerospace uses in comparison with conventional CCCs

2006 GPTMS, TEOS, ZrTPO

$\mathrm{OIH}$ coatings provided corrosion protection and may be used as an alternative for pretreatment of the substrate

GPTMS, TMOS

GPTMS, TEOS

Formation of resilient films with good barrier properties

$\mathrm{OlH}$ prevented the corrosion of the substrate

HEPA, ICPTES, MAPTMS, AEA

UV-curable OIHs were synthesized and characterized with good adhesion to the substrate

GPTMS, TEOS

Film provided an impenetrable barrier to water and corrosive agents

Transparent coatings obtained by UV curing adhered well and were robust in scratch and abrasion tests

GPTMS, TEOS

OIH coatings showed good corrosion resistance in contact with an $\mathrm{NaCl}$ solution

GPTMS, TEOS

GPTMS, MTMS

OlH films provided an effective barrier to water and corrosive agents with a good corrosion resistance

$\mathrm{OIH}$ coatings were uniform, continuous, crack-free and acted as an efficient barrier against corrosive electrolytes

2008 TFPTMOS, TMOS

GPTMS, TEOS

GPTMS, TEOS, APTMS

GPTMS, ZrTPO, TIPT, TBADP

GPTMS, ZrTPO

$\mathrm{OIH}$ film prevented infiltration of $\mathrm{H}_{2} \mathrm{O}$ and limited the exposure of corrosive elements to the substrate

Incorporation of different inhibitors into the silane solution enhanced protection effectiveness of the OIH film

$\mathrm{OIH}$ coatings with good thermal stability and excellent corrosion protection under open-circuit conditions

OlH films showed good anticorrosive performance and excellent adhesion

Studies about the impact on the barrier properties of the OIH sol-gel coatings due to the addition of corrosion inhibitors

PDMSU

PDMSU/PrOH coatings showed improved corrosion behavior when compared to PDMSU/EtOH coatings

TEOS, MAPTS, $\mathrm{SiO}_{2}$

GPTMS, TMOS

$\mathrm{OIH}$ sol-gel coatings promoted substrate corrosion protection and the presence of inhibitors was studied

Creation of a dense crosslinked OlH coating improved substrate corrosion protection

GPTMS, MTMS

Uniform and crack-free coating was obtained reducing corrosion current

MAPTS, TEOS

2009 TEOS, MAPTS, EGDMA, $\mathrm{SiO}_{2}$. GPTMS, MTMS, PR

TEOS addition into the coating enhanced the electrochemical corrosion resistance

Multilayer coatings enhanced the corrosion resistance

Corrosion current of the coated substrates decreased when compared to the bare substrate

TEOS, MPS, HEMA

Electrochemical measurements displayed better barrier properties than the uncoated substrate

GPTMS, TEOS

$\mathrm{OIH}$ films created provided excellent barrier and corrosion protection compared to bare substrate 
Table 4: Continued

Year

Precursors

Results and conclusions

References

GPTMS, TEOS, MTES, BPA,

$\mathrm{SiO}_{2}-\mathrm{NP}$

TEOS, MPTMS, PTMS

BTMSE, MPTMS

TEOS, APTMS, IPDIC, HMDIC, TDIC

$\mathrm{OIH}$ gel coatings with uniform thicknesses and nanoparticle distribution

154

reduced the corrosion rate

Addition of inhibitors to OlH coatings led to an improvement of active

155 corrosion protection

OIH coatings improved the corrosion protection of metals

156

OIH gel coatings showed improved corrosion resistance compared to 157 commercial nonchromate pretreatments

2010 TEOS, MAPTS, $\mathrm{SiO}_{2}$, EGDMA, GMA

GPTMS, ZrTPO

structure of the sol-gel film

Hydrotalcite addition to sol-gel films improves the corrosion resistance of the coated substrate

GPTMS, ZrTPO

MAPTS, ZrTPO

Metallic surface treatment influences the corrosion resistance of the coated substrate

Zirconium nanoparticles significantly improved the performance of the OIH coatings

GPTMS, TMOS

GPTMS, TMOS

TEOS, APTES, ECO

Cerium nitrate was excellent for self-healing of the $\mathrm{OIH}$ coating, while cerium chloride had no obvious effect

OlH coating showed good corrosion resistance

Corrosion tests showed excellent performance providing protection to the substrate

GPTMS, ZrTPO

APTMS, IOTMS, ICPTES PFOTES

$\begin{array}{ll}\text { Crack-free sol-gel coatings with improved corrosion protection were } & 164\end{array}$ produced on the alloy surface

OIH coatings exhibited good corrosion inhibition

158

115

159

160

161

162

163

167

(SiloXel) silane-I, silane-II, silane-

III, TiPT

BTSTS

SiloXel acted as an invulnerable barrier against corrosion of the substrate

Substrate covered by film and by silane conversion coatings showed better corrosion performance

2011 GPTMS, ZrTPO

GPTMS, TEOS, BPA, APTES, MTES, $\mathrm{SiO}_{2}$ GPTMS, TMOS

GPTMS, TEOS

MAPTS, $\mathrm{Nb}\left(\mathrm{OCH}_{2} \mathrm{CH}_{3}\right)_{5}$

2012 GPTMS, $\mathrm{Al}\left(\mathrm{O}^{\mathrm{s}} \mathrm{Bu}\right)_{3}$

GPTMS, TMOS

GPTMS, TEOS, BPA, APTES, MTES, $\mathrm{SiO}_{2}$

GPTMS, TEOS, MTES, BPA

GPTMS, ZrTPO

Addition of as-synthesized hydrotalcite to the $\mathrm{OlH}$ film increased the barrier properties

Increasing the doping level of inhibitors did not lead to improvement of the corrosion resistance

Corrosion protection of substrates by aromatic diamine crosslinked $\mathrm{OlH}$ sol coatings was demonstrated

Coatings exhibited a good anticorrosion performance

Inclusion of niobium into the matrix significantly improved the coating corrosion protection properties

Study of the inhibitor concentration influence on anticorrosion and mechanical properties of the $\mathrm{OlH}$ coating

Studies on synthesis and structure of an OIH coating deposited on the substrate

$\mathrm{OIH}$ coatings doped with cerium and transition metals showed promising corrosion protection properties

OlH coating without additives provided a good corrosion protection of the substrate

Zeolite microparticles used as reservoirs for $\mathrm{Ce}$ (III) were introduced into $\mathrm{OIH}$ coatings enhancing the corrosion protection of the substrate compared to the blank OIH coating

GPTMS, ZrTPO

$\mathrm{OIH}$ coating corrosion properties were improved when red mud particles added were previously calcined

GPTMS, MTMS

TEOS, MTES

$\mathrm{OIH}$ coatings showed to improve corrosion protection of the substrate

$\mathrm{OIH}$ films doped with $1 \mathrm{~mol} \%$ of lanthanum oxide induced a delay on the corrosion of the substrate

GPTMS, DETA, ER Coatings doped with inhibitor provided long-term corrosion protection of the substrate 
Table 4: Continued

Year

Precursors

Results and conclusions

References

2013 GPTMS, TEOS

OlH coatings with good mechanical and adhesive properties were

TEOS, MTMS

produced by optimization of the process parameters

Investigation of dopants within the OIH system on the bond strength of 183 the coating and the substrate

GPTMS, ZrTPO

OIH coating containing cerium molybdate nanowires improved the corrosion protection of the substrate

GPTMS, TEOS

$\mathrm{OlH}$ coatings showed good corrosion barrier properties and the doped ones revealed self-healing behavior

GPTMS, MTMS

OIH showed good adhesion to the substrate and "appreciable" corrosion resistance

GPTMS, TEOS, MTES

Corrosion protection of the $\mathrm{OlH}$ coatings doped with sodium

GPTMS, TEOS montmorillonite and $\mathrm{Ce}$ (III) was improved

Pretreatment with the $\mathrm{OIH}$ delays the access of aggressive species to the barrier layer

GPTMS, TEOS

OIH coatings protected the substrate against corrosion

$\mathrm{OlH}$ showed good adhesion to the substrate, smooth, crack-free, and good corrosion resistance

GPTMS, TEOS

Proper choice of parameters led to OIHs that protect the substrate against corrosion

TEOS, APTES, ECO, TIPT

OlH films showed good adhesion to the substrate and good corrosion protection

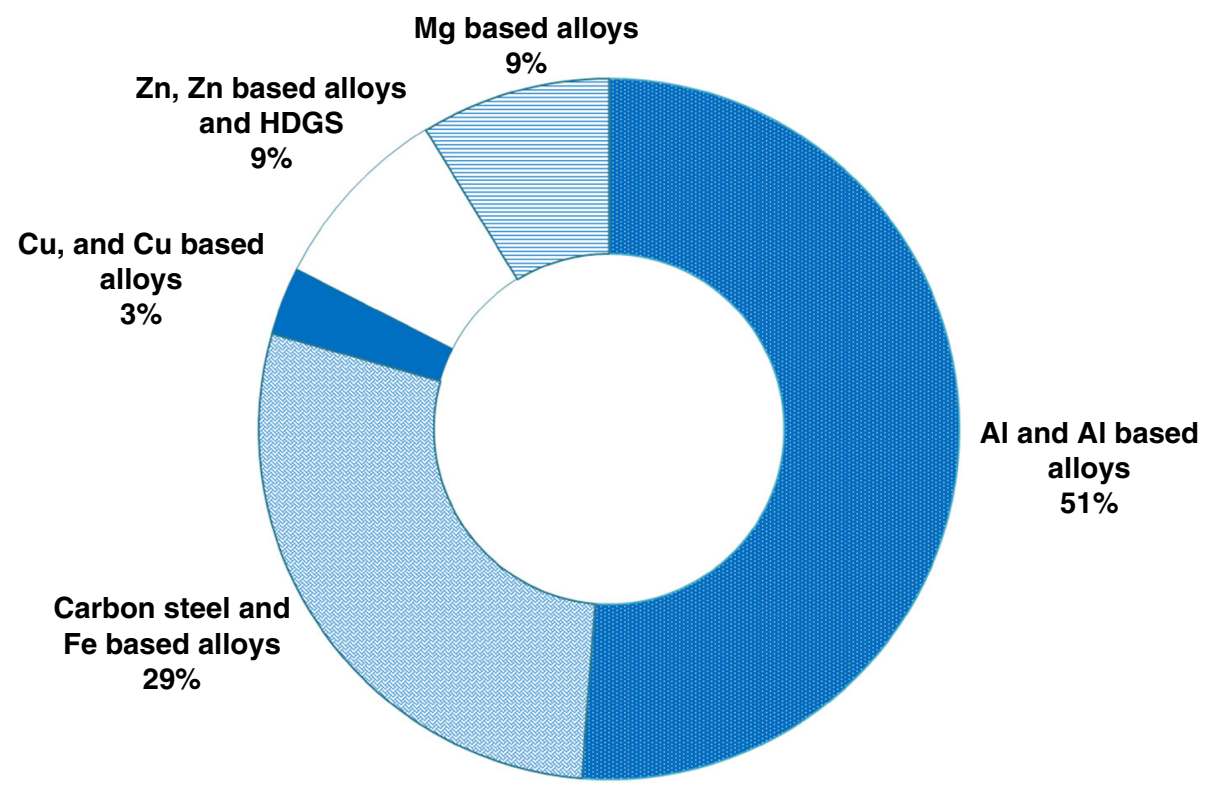

Fig. 11: Reported substrates coated with OIH (class II) gel coatings based on siloxanes (i.e., at least one of the precursors used is based on siloxanes) (2001-2013)

based on siloxanes (i.e., at least one of the precursors used is based on siloxanes) have been produced and tested on aluminum-based alloys. As shown (Table 4), research efforts in coating development for this specific set of materials are particularly strong and are not only focused on corrosion protection but also on aspects such as changing surface hydrophobicity/hydrophobility. For aluminum-based alloys, more precursors were tested than for CS and steel-based alloys substrates (Table 4). Considering the information gathered, half of the published papers were applied to aluminumbased alloys (Fig. 11). It should also be noted that the extensive research in seeking protective coatings for aluminum-based alloys against corrosion has been extensively championed by the aviation industry since it is the most commonly used material. 


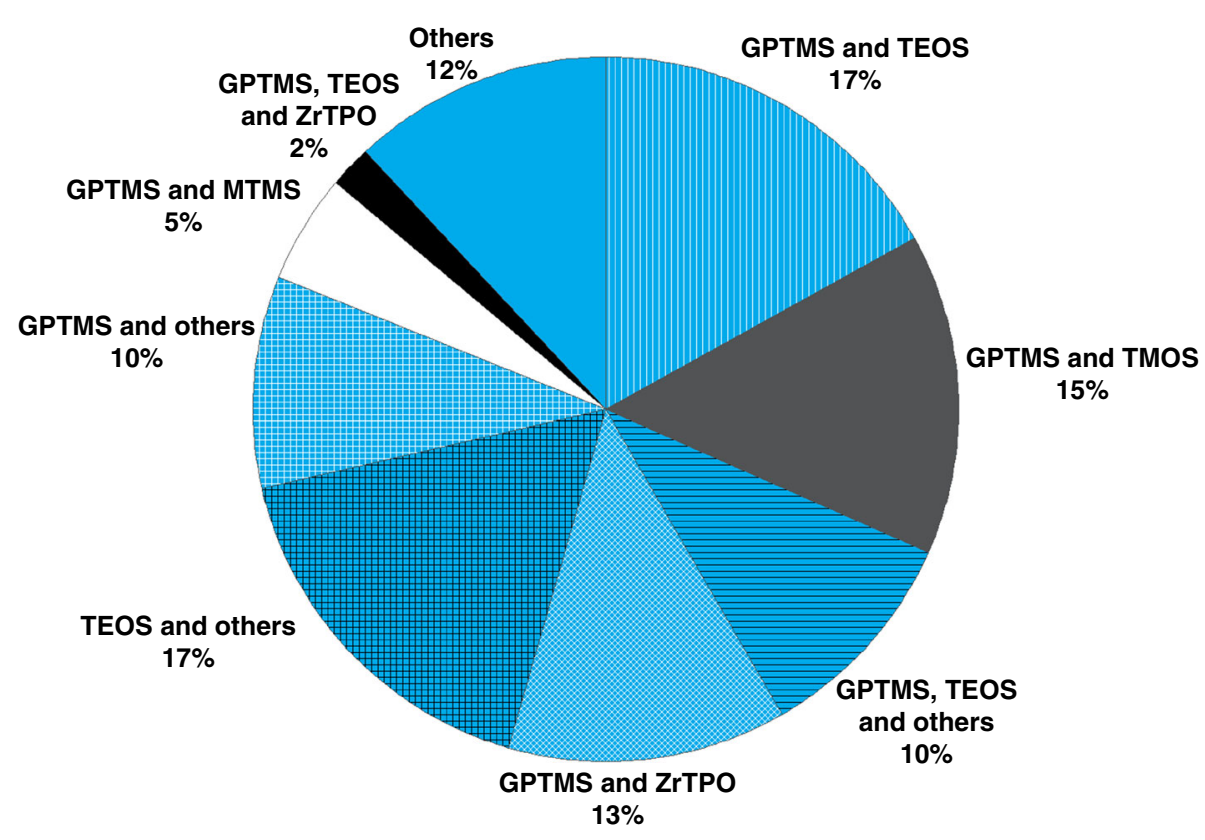

Fig. 12: Precursors used for the production of OIH (class II) gel coatings based on siloxanes (i.e., at least one of the precursors used is based on siloxanes) for aluminum-based alloys (2001-2013)

Considering all the information gathered in Table 4, Fig. 12 shows that $12 \%$ of the OIHs (class II) based on siloxanes reported were produced without using TEOS, GPTMS, TMOS, ZrTPO, and MTMS precursors. It is also shown that TEOS is present in $46 \%$ and GPTMS in $72 \%$ of the publications found for aluminum-based alloys. The collected data also shows that the research focuses mostly on the use of TEOS, GPTMS, TMOS, and ZrTPO and includes, in some cases, the performance of coating materials with embedded corrosion inhibitor species and the deposition of multilayers produced by several depositioncuring cycles.

The intensive use of TEOS is explained by the reasons stated in the previous section, with a lower price than MTMS or ZrTPO, boosting the search for effective OIH coatings using this specific precursor.

The use of GPTMS reported in $72 \%$ of the publications found for these substrates may be explained by the fact that this precursor is a combination of two different components, in particular, glycidoxy (organic) and silicon alkoxy (inorganic) groups. It can thereby form, at the same time, an organic network through the polymerization of glycidoxy groups and an inorganic network through the hydrolysis and subsequent condensation reactions of alkoxy groups. ${ }^{134}$ Moreover, it can be used as a binder in organic-inorganic silicabased systems increasing the density and improving adhesion to the substrates. ${ }^{125}$ It should also be mentioned that this precursor has an epoxy terminal group that exists as a component of commercially available epoxy glues that have an intensive industrial and domestic use for a large variety of purposes and application.
The most recent publications (since 2007) also showed that the innovations for coatings on these substrates are moving toward self-healing coatings doped with nanocontainers able to release entrapped corrosion inhibitors. ${ }^{193-195}$ The majority of the OIH coatings studied showed promising performance in protecting the aluminum-based alloys against corrosion. Some of the OIH coatings studied have reached a remarkable degree of development and the next step will undoubtedly be large-scale industrial production and marketing.

\section{OIH coatings for corrosion protection of copper-based alloys}

Copper and copper-based alloys are versatile materials. This group of alloys has a wide application in sculptures, kitchen utensils, heat exchange tubes, tube sheeting, valves, and piping in seawater and fresh water systems. ${ }^{65}$ Copper shows excellent corrosion resistance and scaling, high mechanical strength, high temperature resistance, and lifetime resistance to UV degradation. However, in wet environments its corrosion processes are accelerated. OIH sol-gel coatings have also been investigated for the protection of copper and the few studies found are summarized in Table 5.

Figure 12 shows that only $3 \%$ of the considered papers report tests using OIH class II based on siloxanes (i.e., at least one of the precursors used is based on siloxanes) and Table 5 shows that the most used precursor was GPTMS.

The reduced number of publications could be explained by several reasons. The native copper oxide 
Table 5: Studies on corrosion protection using OIH (class II) sol-gel coatings on copper and copper alloys substrates (2001-2013)

\begin{tabular}{|c|c|c|c|}
\hline Year & Precursors & Results and conclusions & References \\
\hline 2003 & GPTMS, MTMS, $\mathrm{SiO}_{2}$ & $\begin{array}{l}\text { OIH coatings show good resistance to UV and effectively delayed corrosion } \\
\text { on the substrates }\end{array}$ & 41 \\
\hline 2008 & GPTMS, MPTMS & Incorporation of $5 \mathrm{~mol} \%$ of MPTMS enhanced the corrosion resistance & 196 \\
\hline 2009 & BTMSE, MPTMS & OIH coatings have improved the corrosion protection of the substrate & 156 \\
\hline \multirow[t]{2}{*}{2013} & TEOS, GPTMS & $\begin{array}{l}\text { Best corrosion protection was achieved when the amount of BTAH equals the } \\
\text { molar number of epoxy group in the OIH coating }\end{array}$ & 197 \\
\hline & TEOS, TMCS, HMDS & $\begin{array}{l}\text { OIH coatings prepared in alkaline conditions are more stable and those } \\
\text { prepared with HMDS were not affected by corrosion }\end{array}$ & 198 \\
\hline
\end{tabular}

layer is mechanically weak and at room temperature consists mainly of $\mathrm{Cu}_{2} \mathrm{O}$ or both $\mathrm{Cu}_{2} \mathrm{O}$ and $\mathrm{CuO}$ with a thickness of a few nanometers and is usually contaminated by carbon. ${ }^{199-201}$ Additionally, the oxide layer is not easily wettable by the sol solution, ${ }^{200}$ therefore the adherence between $\mathrm{OIH}$ sol-gel coatings and the substrate is compromised. Deflorian et al. ${ }^{202}$ showed in 2008 that GPTMS does not establish an interaction with the native copper oxide layer. Moreover, 1,2,3benzotriazole (BTAH, $\mathrm{C}_{6} \mathrm{H}_{5} \mathrm{~N}_{3}$ ) is an effective corrosion inhibitor for copper and its alloys in different environmental media, as demonstrated by Finšgar and Milošev $^{203}$ in a paper published in 2010, where the most significant work made using BTAH was reviewed. Therefore, it is neither a huge concern nor an urgent need to search for alternatives against corrosion for these types of substrates and alloys as BTAH shows to be a very effective corrosion inhibitor.

\section{OIH coatings for corrosion protection for zinc-based alloys HDGS}

Zinc is used as an additive in certain rubbers and paints, in the production of alloys, and as coating through several methods, such as electroplating, thermal spraying, sherardizing, hot dipping, etc.

Hot-dip galvanizing (HDG) is considered the most important zinc coating process to protect building structures, such as roofs and exterior walls, and constituent parts of cars and boats. Due to its superior corrosion protection by serving simultaneously as a sacrificial anode and as a physical barrier, zinc coatings are widely used. However, during contact (such as storage and transportation) with humid environments, the zinc surfaces form corrosion products (white rust, Fig. 13) easily due to the high electrochemical reactivity.

Hot-dip-galvanized steel (HDGS) used in reinforced concrete structures is an example of the many applications of HDGS and has been recognized as an effective measure to improve the service life of reinforced concrete structures. Although, when HDGS

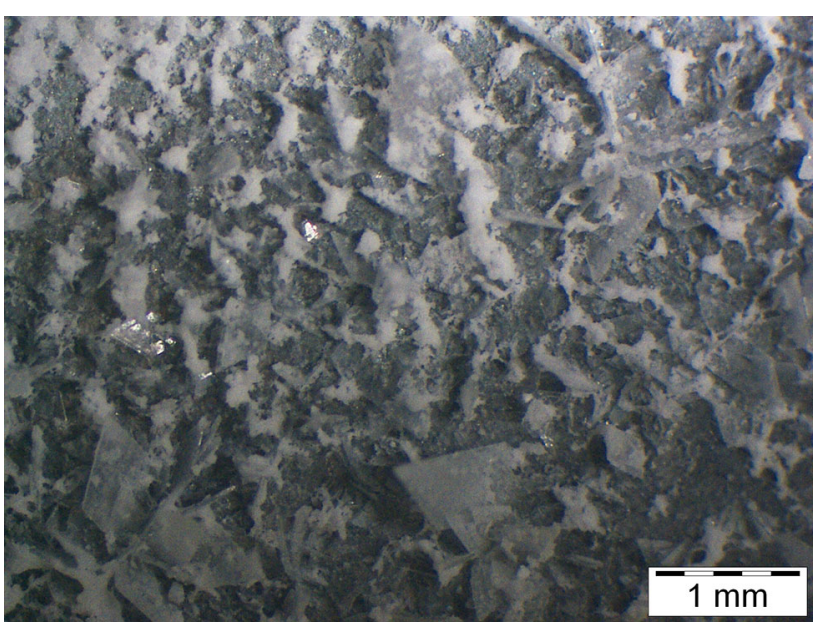

Fig. 13: Stereomicroscopic observation of HDGS surface magnified 20 times showing the corrosion products (white rust)

is embedded in fresh concrete, which is a highly alkaline environment, the zinc coating corrodes until passivation occurs and the concrete hardens. Due to the initial high corrosion rate of the zinc when in contact with fresh concrete, part of the zinc layer may be removed, compromising the galvanic protection of the underlying steel in the long term. Moreover, the hydrogen evolution during the corresponding cathodic half-cell reaction will increase the porosity of the adjacent cement paste and, therefore, reduce the bond strength between the rebar and the concrete. To minimize the zinc corrosion, either during storage and transportation within humid environments or when embedded in fresh concrete, CCCs have been extensively used. Nevertheless, these should be replaced in the near future due to their high toxicity. Several studies have been made to search for viable alternatives to the use of the CCC. However, few papers have been found using OIH sol-gel technology and these are listed in Table 6.

Considering all the information gathered (Table 6; Fig. 10), it was shown that only $9 \%$ of the papers 
Table 6: Studies on corrosion protection using OIH (class II) sol-gel coatings on zinc, zinc-based alloys, and HDGS substrates (2001-2013)

\begin{tabular}{|c|c|c|c|}
\hline Year & Precursors & Results and conclusions & References \\
\hline 2001 & ER and BPA & Results showed effective protection of the metallic substrate & 204 \\
\hline 2004 & MAPTS, TMOS & $\begin{array}{l}\text { Anticorrosive performance of the } \mathrm{Ce}^{3+} \text { ions trapped within the } \mathrm{OIH} \text { network } \\
\text { occurred by the self-repairing mechanism of the inhibitor }\end{array}$ & 205 \\
\hline \multirow[t]{2}{*}{2006} & TEOS and PDMMS & OIH coating improved corrosion protection of the substrate & 206 \\
\hline & TEOS and MTES & $\begin{array}{l}\text { Protective properties of } \mathrm{OlH} \text { coating and its dependence on the sintering } \\
\text { temperature were studied and shorter sintering times are recommended }\end{array}$ & 207 \\
\hline 2009 & GPTMS, TEOS, MTES & $\begin{array}{l}\text { Results showed that the OIH ensured a barrier effect against water and } \\
\text { oxygen and acted as an adhesion promoter between the substrate and the } \\
\text { coating }\end{array}$ & 208 \\
\hline \multirow[t]{2}{*}{2010} & GPTMS, TEOS, MTES & $\begin{array}{l}\text { OIH filled with montmorillonite nanoparticles and cerium oxides enriched } \\
\text { montmorillonite nanoparticles were tested. Cerium oxides did not improve } \\
\text { the corrosion protection of the OIH film }\end{array}$ & 209 \\
\hline & GPTMS, TEOS, MTES & Effect of the EPD conditions on HDGS pretreated with OIH was studied & 210 \\
\hline 2011 & TIPT, PAPTES & $\begin{array}{l}\text { Results showed that the OIH coating offered good corrosion protection for the } \\
\text { substrate }\end{array}$ & 88 \\
\hline \multirow[t]{2}{*}{2012} & GPTMS, TEOS, MTES & $\begin{array}{l}\text { Montmorillonite clay was modified to obtain } \mathrm{Ce}(\mathrm{III}) \text { montmorillonite clay and it } \\
\text { was successfully incorporated in the OIH coating }\end{array}$ & 211 \\
\hline & AEAPS, epoxy resin & $\begin{array}{l}\text { OIH coatings with nanocontainers loaded with corrosion inhibitor enhanced } \\
\text { the anticorrosive properties compared to the coatings with empty } \\
\text { nanocontainers or only with the inhibitor }\end{array}$ & 212 \\
\hline \multirow[t]{4}{*}{2013} & GPTMS, TEOS, MTES & $\begin{array}{l}\text { The beneficial effect of Na-Montmorillonite sonication on the corrosion } \\
\text { properties of the OIH was confirmed }\end{array}$ & 104 \\
\hline & GPTMS, BPA & OIH coatings doped with $0.05 \mathrm{M}$ of cerium nitrate improved barrier properties & 213 \\
\hline & BTSE, ERE & $\begin{array}{l}\text { Substrates coated with OIH by EPD showed improved corrosion protection } \\
\text { than the substrates coated with OIH by immersion }\end{array}$ & 214 \\
\hline & ICPTES, Jeffamine ${ }^{\circledR}$ & $\begin{array}{l}\text { OIH coatings minimized the } \mathrm{H}_{2} \text { evolution on the HDGS when embedded in } \\
\text { fresh mortar }\end{array}$ & 215 \\
\hline
\end{tabular}

published between 2001 and 2013 tested OIH (class II) gel coatings. The most frequently used precursors were GPTMS, TEOS, and MTES and their use represented $36 \%$ of the total studies found and reported (Table 6). The small amount of published papers using OIH solgel coatings based on siloxanes (i.e., at least one of the precursors used is based on siloxanes) may be due to the focus on searching for new green conversion coatings $^{216-221}$ based on molybdate, ${ }^{216-218}$ permanganate, ${ }^{219,220}$ silicate, $^{222-224}$ titanate, ${ }^{225,226}$ rare earth salts, ${ }^{227-230}$ tungstate, ${ }^{230,232}$ and vanadate $^{233}$ compounds.

\section{OIH coatings for corrosion protection of magnesium-based alloys}

Magnesium is employed as a structural load bearing material exploiting its chemical and metallurgical properties. These alloys are used as a sacrificial anode to protect steel against corrosion in circumstances such as the protection of underground pipelines and to increase the service life of household hot water tanks. In 2010, $\mathrm{Guo}^{2}$ stated that due to the low weight and excellent mechanical properties of magnesium and its alloys, innovative magnesium alloys, or enhanced alloys with superior properties should be developed and in-depth research should be performed. Several alloys have been developed in order to obtain a range of properties and features that can fulfill the needs of a wide range of uses. ${ }^{2,65}$

The wide range of potential applications of magnesium and magnesium-based alloys makes it incredibly attractive for engineering uses, mainly in the aerospace and automobile industries due to the low density and high specific stiffness. Currently, magnesium-based alloys are under study and alloys referred to as AZ91D, AM60B, AM50A, and AS41B have been developed for die casting processing giving rise to alloys with superior corrosion resistance when compared to the aluminum die casting alloys frequently used. In spite of these advantages their application is still limited by their high corrosion vulnerability in aqueous environments, particularly in the presence of chloride ions. ${ }^{65}$

The publications found about the use of OIH (class II) coatings based on siloxanes (i.e., at least one of the precursors used is based on siloxanes) are summarized in Table 7. Considering all the information gathered, Fig. 10 shows that $9 \%$ of the papers were about 
Table 7: Studies on corrosion protection using OIH (class II) sol-gel coatings on magnesium substrates published since 2001

\begin{tabular}{|c|c|c|c|}
\hline Year & Precursors & Results and conclusions & References \\
\hline 2005 & MAPTS, MPTMS, $\mathrm{SiO}_{2}$ & $\begin{array}{l}\text { OIH coatings provided corrosion protection by sealing pores in the anodized } \\
\text { layer and acting as a barrier. The application of multilayers eliminated the } \\
\text { diffusion paths for corrosive species }\end{array}$ & 234 \\
\hline 2006 & TEOS, PHS & $\begin{array}{l}\text { Besides the barrier coating on a metal surface, the phosphonate } \\
\text { functionalities reacted with the surface of the substrate increasing both } \\
\text { adhesive and corrosion resistance properties of the coatings }\end{array}$ & 235 \\
\hline 2008 & GPTMS, ZrTPO, TBADP & $\begin{array}{l}\text { A well-adhered OIH gel coating for the substrate was obtained and the } \\
\text { effectiveness of corrosion protection was confirmed }\end{array}$ & 236 \\
\hline \multirow[t]{4}{*}{2009} & $\begin{array}{l}\text { TEOS, MTES, DEDMS, } \\
\text { PHS, GPTMS }\end{array}$ & $\begin{array}{l}\text { Corrosion protection was improved by implementing an interpenetrating } \\
\text { network coating morphology }\end{array}$ & 237 \\
\hline & TEOS, GPTMS & $\begin{array}{l}\text { Study of the OIH coating properties, characterization and formation } \\
\text { mechanism }\end{array}$ & 238 \\
\hline & GPTMS, TMOS & $\begin{array}{l}\text { Phosphate conversion coating sealed with OIH coating doped with inhibitor } \\
\text { (2-methylpiperidine) showed better corrosion resistance than undoped } \\
\text { coating }\end{array}$ & 239 \\
\hline & TEOS, GPTMS & $\begin{array}{l}\text { Three layers of OIH coatings totally covered the cracks produced on the } \\
\text { molybdate conversion coating first deposited on the substrate and showing } \\
\text { good corrosion behavior }\end{array}$ & 240 \\
\hline \multirow[t]{3}{*}{2010} & ZrTPO, GPTMS & $\begin{array}{l}\text { OIH gel coatings doped with corrosion inhibitor showed improved corrosion } \\
\text { behavior in the protection of the films in comparison with the undoped ones }\end{array}$ & 241 \\
\hline & TMOS, DEDMS & $\begin{array}{l}\text { OIH coatings obtained were evaluated as autonomous protective coatings as } \\
\text { well as a pretreatment prior to acrylic topcoat. OIH coatings doped with } \\
\mathrm{Ce}^{3+} \text { were effective as pretreatments for a final acrylic coating }\end{array}$ & 242 \\
\hline & GPTMS, VTES & Increasing of $\left[\mathrm{Ce}^{3+}\right]$ on the $\mathrm{OlH}$ coating decreases the anticorrosion effect & 243 \\
\hline 2011 & TEOS and MTES & $\begin{array}{l}\text { Precursor ratios }(X 1) \text {, sol dilution }(X 2) \text {, and sintering temperature }(X 3) \text { were } \\
\text { studied for an } \mathrm{OIH} \text { coating. Best conditions obtained for } \mathrm{X} 1=3.36 \text {, } \\
\mathrm{X} 2=1.5 \text {, and } \mathrm{X} 3=222^{\circ} \mathrm{C}\end{array}$ & 244 \\
\hline 2012 & GPTMS, MTES & $\begin{array}{l}\text { Results revealed that the surface conditioning process was a key step to } \\
\text { achieve the required anticorrosion properties of the substrate coated with } \\
\text { the OIH }\end{array}$ & 245 \\
\hline \multirow[t]{2}{*}{2013} & GPTMS, $\mathrm{Al}\left(\mathrm{O}^{\mathrm{s}} \mathrm{Bu}\right)_{3}$ & $\begin{array}{l}\text { OIH coating showed lower thickness in some points offering inferior } \\
\text { protection against corrosive species }\end{array}$ & 246 \\
\hline & $\begin{array}{l}\text { DGEBA, APTES, APTMS, } \\
\text { GPTMS, TMSPh }\end{array}$ & $\begin{array}{l}\text { OIH coatings proposed showed high corrosion resistance with considerable } \\
\text { improvements obtained by the OlHs based on APTMS and APTES }\end{array}$ & 247 \\
\hline
\end{tabular}

magnesium-based alloys and that in $71 \%$ of those publications the most frequently used precursor was GPTMS in combination with others.

Analyzing the available research papers concerning the prevention of corrosion on magnesium alloys, it seems that the research is following another path. ${ }^{248-254}$ Most research focuses on improving the existing magnesium alloy properties ${ }^{249-251}$ or inventing new ones, ${ }^{248,252-254}$ instead of investigating OIH solgel coatings. This line of thought explains the fewer publications found when compared with the research available for aluminum or steel substrates.

\section{Limitations of organic-inorganic hybrid sol-gel coatings for corrosion protection}

In the last two decades, the existing knowledge about sol-gel processing and relations between structure and properties has had an exceptional development. Consequently, the research efforts on this particular area of materials science have grown, allowing scientists to gain knowledge on how to develop new OIH gel materials.

Despite the advantages of combining different properties, synthesis constraints still remain. The major limitations of sol-gel processing for coating metals are delamination, crackability, adhesion, and thickness limits. Assuring a uniform distribution on the substrate and thermal treatments (curing/drying) are crucial factors to ensure the quality of anticorrosive coatings. ${ }^{3}$ Cracks may affect several properties and are detrimental to the substrate in wet corrosive media. Sendova et al. ${ }^{255}$ produced silicate sol-gel coating films with four different crack patterns, achieving reproducible patterns by controlling the film deposition parameters. These authors showed that the geometric characteristics of the crack patterns were related to the 
thickness of the film and the deposition parameters. Latella et al. ${ }^{256}$ synthesized and assessed the adhesion behavior and mechanical properties of OIH coatings. It was confirmed that the presence of a thermally grown oxide layer on the substrate, prior to the OIH sol-gel deposition, had an important role on the adhesion behavior (quality) between the film and the substrate. They also showed that the relation between the structure of the film and the mechanical properties of the coatings were influenced by the nature/characteristics of the organic substituent.

Mammeri et al. ${ }^{39}$ investigated and analyzed the mechanical properties of OIH gels reported by several authors and concluded that those properties were dependent on their micro- and nanostructures as well as the nature and extent of the organic-inorganic interfaces within the gel matrix.

Some authors showed that when the substrate was subjected to localized plastic deformation due to impact with objects, or extensive plastic deformation due to substrate bending, cracks, and delamination developed easily in the thin films. ${ }^{3,55}$ Others showed that electrodeposition (EPD) techniques provided fairly thick crack-free sol-gel-derived coatings when compared either to dip or spin coating techniques. ${ }^{64,195}$ Castro et al. ${ }^{257}$ combined the sol-gel method and the EPD process to prepare thick coatings onto metallic substrates obtaining crack-free deposits up to $20 \mu \mathrm{m}$ in thickness after drying and crack-free glass-like coatings of $12 \mu \mathrm{m}$ in thickness after sintering at $500^{\circ} \mathrm{C}$ for 30 min. ${ }^{257}$ The characterization of OIH materials by potentiodynamic methods showed that they have good performance against corrosion. Most of the studies reported in the literature were on planar samples and the films were deposited by dip or spin coating processes. Objects with complex shapes are far more challenging to coat using these methods, particularly if a uniform thickness is a strict requirement. For these reasons, additional coating methods besides spraying, dipping, spinning, and EPD are expected to be extensively tested and developed in the near future. ${ }^{3}$

The deposition method selected might be a limiting variable as in certain circumstances it could negatively influence the performance of the $\mathrm{OIH}$ coating applied on the substrate. If the deposition method chosen is not the correct one, even with an OIH material displaying excellent barrier properties, the coating performance is compromised. The available deposition methods do not ensure fully uniform coatings, particularly when dip-coating systems for the deposition of low viscosity OIH gel precursors are used. Representative SEM images and EDS analysis data obtained for the HDGS samples coated with two matrices of the OIHs synthesized and deposited on the substrate by dip-coating method as described elsewhere ${ }^{215}$ are shown in Figs. 14 and 15 .

It can be observed that the distribution of the $\mathrm{OIH}$ coatings is not uniform. As shown by EDS analysis, the gray areas correspond to the OIH coating (assigned by high peaks of $\mathrm{C}, \mathrm{Si}$, and $\mathrm{O}$ ) and the lighter areas are representative of the substrate (HDGS). In the absence of the OIH coating, the peak assigned to zinc is particularly intense. It is also highlighted that it is difficult to achieve a uniform distribution even with a triple-dip step process as shown in Fig. 15a. Nevertheless, these obstacles can be overcome by the use of intermediate deposition and curing steps. However, the increase in the number of steps involved in coating methods make these procedures extremely complex and time consuming. As such, a compromise between the improvement of the final material properties and the associated costs should be made.

Another important limitation considered by the consumer industry is the difficulty in assessing the behavior of the coating against corrosion after being exposed to the environment. In certain cases, such as underground pipelines and storage tanks, visual observation is impossible without exceptional efforts and
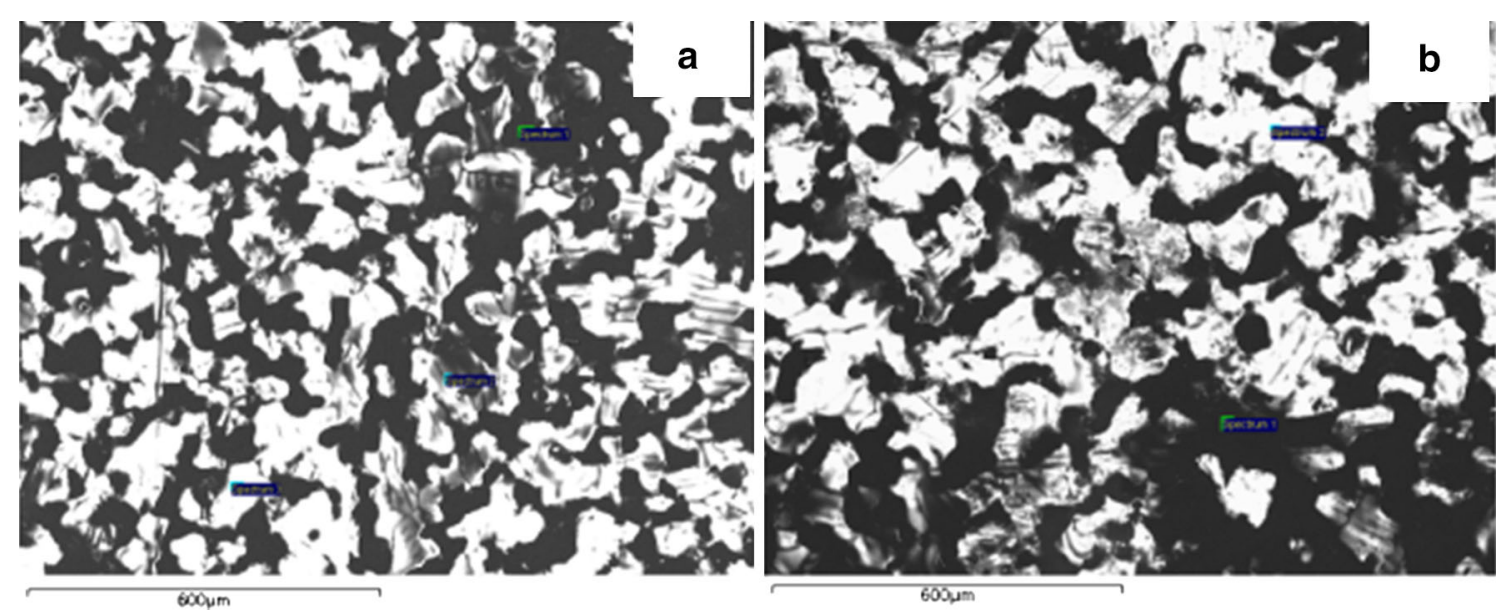

Fig. 14: SEM images of HDGS samples coated with the same OIH matrix by dip step method (a) one layer and (b) two layers 

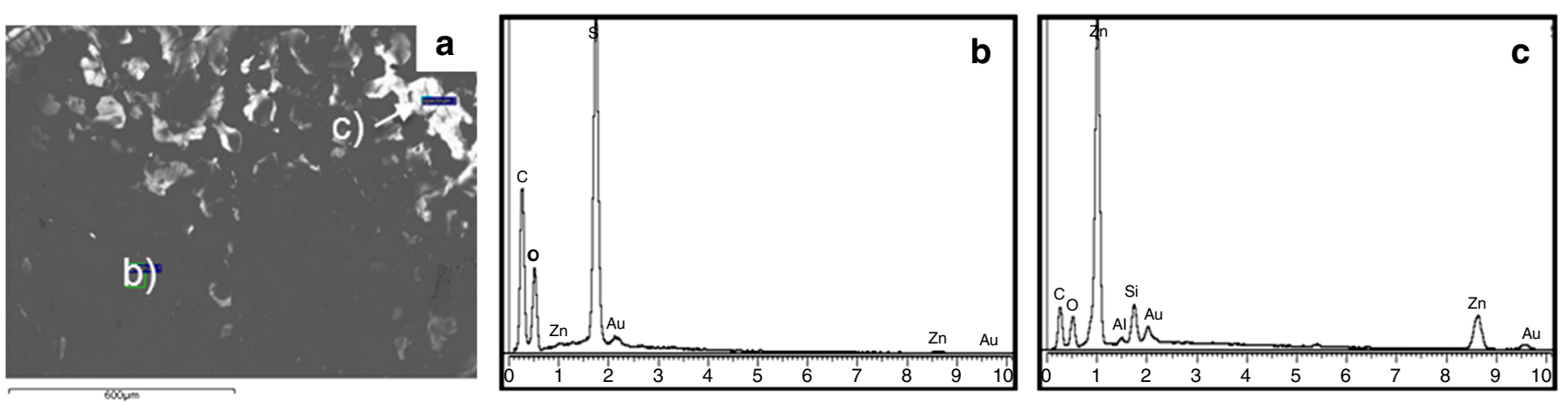

Fig. 15: (a) SEM image of HDGS samples coated with three layers of OlH by dip-coating method; (b) and (c) show EDS spectra obtained by scanning two different regions coated samples with three layers of OlH using dip-coating method

costs. In such situations, research should be carried out by pre-evaluating the performance and lifetime of the protective coatings, on lab or at a pilot scale, to plan the adequate maintenance/replacement interventions or by the development of appropriate sensors and monitoring methods based on self-sustainable and remote control devices.

Arkles $^{258}$ in 2001 published a paper about the commercial applications of the synthesized OIH gel materials and, according to him, these show viability in the market either owing to uncommon properties that allow new end-use applications or significantly better cost/performance relation when compared with the available materials.

Until now, the traditional CCCs confer the best corrosion protection known at controlled costs making this area even more challenging leading to continuous research for contemporary OIH materials that fulfill the same properties and performances exhibited by CCCs coatings.

It is noteworthy that no report has yet been found, either in industrial or academic research, of OIH solgel coatings with the same production costs and of equal or superior corrosion performance to traditional conversion layers used processes (chromating and phosphating). As far as authors are aware, no systematic theoretical and experimental approach on how to evaluate the viability, efficiency, and stability of $\mathrm{OIH}$ sol-gel coatings, has been implemented and is far from being established. The present situation demands further research and innovation efforts to guarantee the success of the application of OIH sol-gel coatings as metal corrosion protection.

\section{Future and research challenges on organic- inorganic hybrid materials for corrosion protection}

Nowadays, metal corrosion protection is strongly reliant on organic and organic-inorganic coating technology, as it is a cost-effective mean of providing practical protection against corrosion for easily corrodible metallic structures and objects. The quality and effectiveness of corrosion control by coatings is assumed by many users to be low cost and easy to achieve. For these reasons, the users of corrosion control coatings often choose these by cost and appearance and not by cost effectiveness, which can be measured by their performance and the lifetime of their behavior. However, with high labor costs and the difficulties found in recoating large, buried, complex or difficult to reach objects, more coatings users are focusing on the total costs of corrosion prevention and control. A coating system that increases the lifetime of the product but is somewhat more expensive, due to the initial application method, will pay for itself in reduced maintenance costs and reduced need for expensive recoating. Following this line of thought, the cost analysis of the corrosion protection provided by coatings must lead to further research into measuring and predicting the pot life of the protective properties of these materials.

It is undeniable that future applications and research should be focused primarily on the investigation of more environmentally friendly precursors and industrial colloid particles to replace the traditional precursors in the formation of sol-gel protective coatings without changing their general properties. Among the most critical constraints identified are the coating's mechanic strength and good adhesion to metallic substrates.

In spite of the large number of papers published on this subject, no work was found reporting the use of OIH coatings to stop and prevent corrosion on already damaged substrates as well as studies testing such materials for significant periods of time. The evaluation of whether OIH coatings have the ability to minimize/ stop damage caused by corrosion and their durability over time is of extreme importance since OIHs are known for having a limited shelf life due to sluggish condensation reaction kinetics. The products developed for the protection of metallic substrates against corrosion must have a long lifetime. Another conclusion of the detailed analysis of the large set of publications was that studies on the barrier properties of the coatings over time were not found. Therefore, a 
relevant question that must be answered is "How long are OIH coatings used to prevent corrosion able to maintain their barrier properties?" As such, it is vital to undertake long-term tests in the near future as the durability/resistance of $\mathrm{OIH}$ coatings for corrosion prevention remains unknown.

The search for future $\mathrm{OIH}$ gel-based coatings is oriented toward low cost, pollution-free, easily synthesized, and effective corrosion protection OIH coatings that do not generate hazardous waste during their application and removal. Development of OIH coatings with self-healing properties would be a challenging innovation that will contribute in giving an added highvalue to the synthesized materials.

Inspired by living organisms, materials engineers are focusing on developing materials with self-healing properties. According to Ghosh, the term "self-healing" may be defined as "...the ability of a material to heal (recover/repair) damages automatically and autonomously, that is, without any external intervention." ${ }^{259}$ Several authors ${ }^{195,260-272}$ developed and reviewed corrosion protection systems with self-healing abilities. The development of OIH coatings with those properties by incorporating the release of healing agents, reverting crosslinks or using simultaneous technologies such as conductivity; shape memory effect; nanoparticle migration; and co-deposition ${ }^{257}$ might be considered as important achievements.

The development of new OIH coatings with dualbehavior (a protective barrier accumulating the $\mathrm{OIH}$ properties with a self-healing response) is a synergy that will bring benefits and improvements in corrosion prevention, fulfilling the requests needed by the users of coatings technology. This new concept is based on multilayer coatings where inhibitors and self-healing agents are immobilized in one of the layers being isolated from the external media and metal substrate by intermediate layers. ${ }^{273}$ It is important that the implemented procedure to obtain these new systems assures good adhesion and similar thermal expansion coefficients between the layers. This same procedure also relies on an efficient top coating layer barrier protection. Moreover, the immobilization of both selfhealing and inhibitor agents within a layer apart from the metallic substrate, by intermediate layers, prevent side reactions and leakage that may affect the substrate.

Considering the potentialities of the sol-gel method, efficient multilayer coatings could be produced if the adhesion between the metallic substrate and the contact layer is achieved, as well as the adhesion between each one of the different upper layers. Additionally, these materials show efficient barrier properties and the capacity of hosting species with different properties allows the development of an improved multilayer coating that combines corrosion inhibition and self-healing properties.

This paper proposes a model inspired by the one proposed by the authors Hughes et al. ${ }^{273}$ for a multilayer coating system. The protective coating proposed is to be produced in five steps (Fig. 16), using mainly sol-gel methods. The first step involves chemical activation of the metallic surface, aiming to improve further covalent interaction between the $\mathrm{Si}-$ $\mathrm{O}-\mathrm{Si}$ groups of the OIH matrix and the oxo- and/or hidroxo-groups formed on the metallic surface. Additionally, it is expected that this treatment will contribute to improving the uniformity and distribution of the first OIH sol-gel layer deposited, providing full coverage on a smoother substrate than that given by the chemical pretreatment. The second step of the proposed model consists of depositing a thin layer of OIH matrix gel. The sol-gel precursors used to produce this coating material should provide good adhesion with the activated metallic substrate and adequate curing process ensuring appropriate mechanical and support properties to the deposition of a second OIH gel layer. The composition of this and the other layers should be based on the same matrix composition in order to avoid sharp differences of the properties at the interface between the different layers preventing surface/interface tensions. This strategy also contributes to minimizing the differences in thermal and mechanical properties between the different layers. The deposition of this first layer is also necessary to ensure that the inhibitors and any other species, including selfhealing agents, do not migrate toward the metallic surface except when in the presence of external aggressive agents. In this situation, the inhibitor action could be expanded to the vicinity of the metallic surface to stop the spread of corrosion.

As observed by several authors, the relative amount of inhibitor could compromise OIH matrix stability, ${ }^{94,99,117,120,130}$ so the presence of the first OIH layer also contributes to additionally enhance the protection against inhibitor mobility/migration or diffusion toward the metallic surface.

The layer where the inhibitor is immobilized is produced in a third step and under adequate gelling conditions to minimize the curing demanding time and optimize the immobilization of the inhibitor species within this layer. Adjusting the gelling time (viscosity) of the gel precursor (of the deposited coating) by achieving an optimum viscosity value, allows the starting of the curing process immediately and during a short time. This methodology should also obtain a dense and smooth layer with a good adhesion to the previous OIH layer.

The following step consists of producing a third OIH layer containing self-healing agents that contribute to guarantee the reversibility of the damages caused by a variety of factors such as usage, weathering, or loading damage. The reversibility mechanism could be triggered by the entrance of water and ions transported through the topcoat. This mechanism is inspired by the process that has been used for self-healing in polymer composites through the release of a polymerizable healing agent that can bridge cracks after reaction with the appropriate catalysts. ${ }^{274}$ The synthesis procedure to obtain this layer is critical as it should ensure that the 


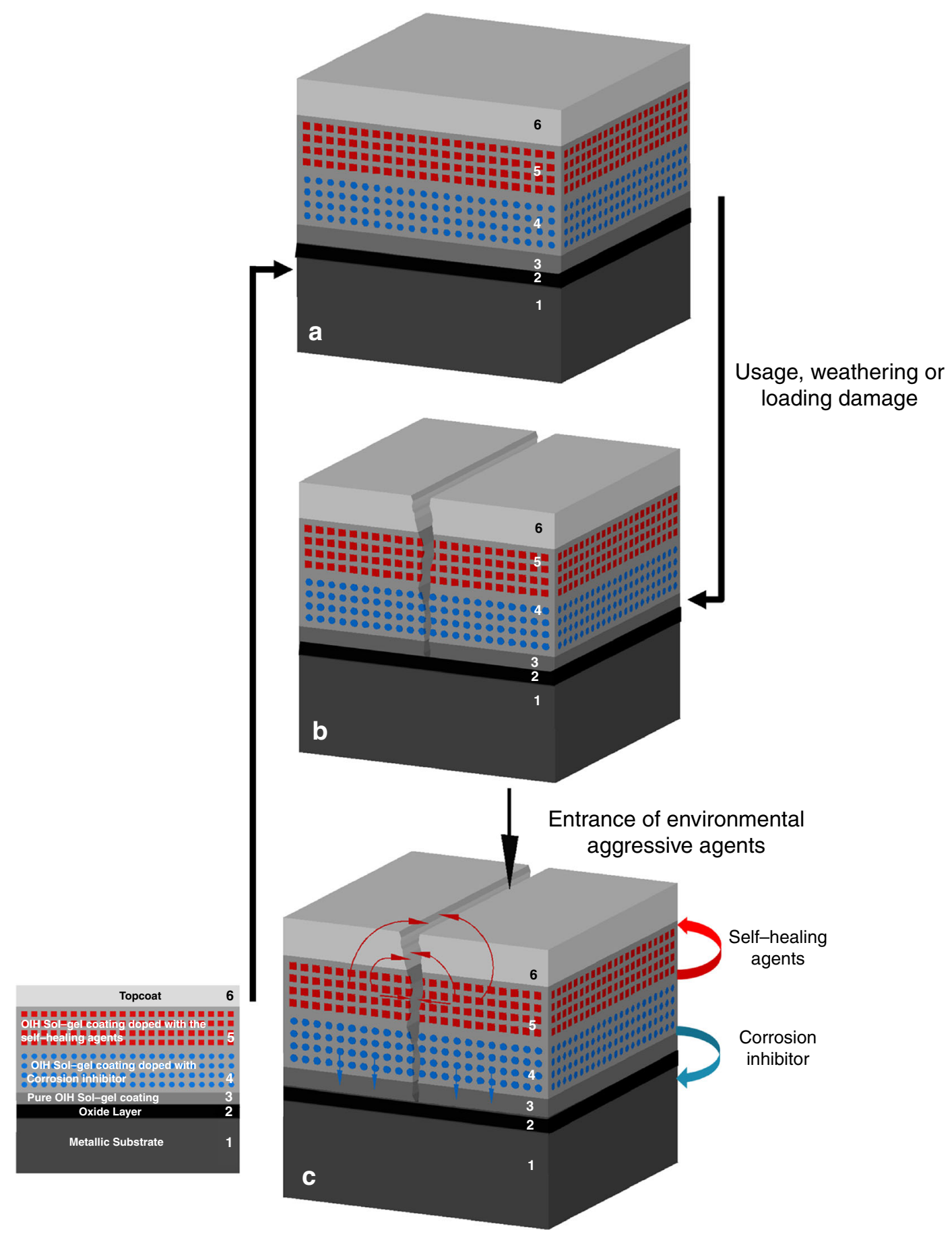

Fig. 16: (a) Multilayer coating system composed of five layers. 1-Metallic substrate; 2-oxide layer; 3-pure OIH sol-gel coating; 4-OIH sol-gel coating doped with a corrosion inhibitor; 5-OIH sol-gel coating doped with a self-healing agent; and 6-Topcoat. (b) Multilayer coating system after damage. (c) Expected behavior of the multilayer coating system behavior when in contact with exterior aggressive agents

self-healing agents dispersed within this OIH layer preserve their properties and mobility after the curing treatment. Finally, a highly hydrophobic topcoat layer should be deposited at mild conditions to combine the barrier effect protection and to avoid any possible degradation of the different OIH-based layers that are beneath. The total thickness of this type of multilayer coating system should be about $16 \mu \mathrm{m}$ considering the use of dip-coating method that allows the production of each OIH layer with an average thickness of $4 \mu \mathrm{m}$. The schematic representation of the proposed multilayer coating system is displayed in Fig. 16. 


\section{Concluding remarks}

Publications between 2001 and 2013 about OIH sol-gel coatings class II based on siloxanes, which were tested to prevent corrosion on metallic substrates, were reviewed. Since the early 1970s, academic interest in $\mathrm{OIH}$ materials has been accelerating and since the 1990s it has become a fast-growing and very complex subject with an almost exponential increase in the number of the scientific publications.

The main driving force in the development of OIHs class II based on siloxanes to prevent corrosion was the search for potential candidates to substitute environmentally unfriendly chromate surface treatments for metallic substrates.

The analysis of the papers published between 2001 and 2013 shows that it is on aluminum-based alloys where higher search efforts for an efficient coating to replace CCCs has been done, followed by steel substrates, zinc and magnesium alloys, with copper alloys in last place. Regardless of the type of substrate, the most frequently used precursors were GPTMS, TEOS, and TMOS.

Tested OIH materials present a large diversity of compositions and enhanced physical, mechanical, and morphological properties, among others. OIH materials show strong potential and are clearly becoming a reality as serious candidates for numerous applications such as smart coatings with "intelligent" self-healing properties and functional protective coatings. Moreover, the OIH sol-gel process shows high potential for the production of multilayer coating systems which are promising environmentally friendly candidates for replacement of the chromate-based pretreatments due to a synergistic effect of good barrier properties and effective "self-healing" action.

Acknowledgments The authors would like to gratefully acknowledge the financial support from Fundação para a Ciência e Tecnologia (FCT) for the $\mathrm{PhD}$ grant SFRH/BD/62601/2009, the financial support by Centro de Química [project F-COMP-01-01024FEDER-022716 (ref. Pest-C/Qui/UI0686/2011)-FEDERCOMPETE] and EU COST action MP1202: HINT Rational design of hybrid organic-inorganic interfaces: the next step towards functional materials.

\section{References}

1. Osborne, JH, "Observations on Chromate Conversion Coatings from a Sol-Gel Perspective." Prog. Org. Coat., 41 280-286 (2001)

2. Guo, K, "A Review of Magnesium/Magnesium Alloys Corrosion and Its Protection." Recent Pat. Corros. Sci., 2 13-21 (2010)

3. Guglielmi, M, "Sol-Gel Coatings on Metals." J. Sol Gel Sci. Technol., 8 443-449 (1997)
4. Twite, RL, Bierwagen, GP, "Review of Alternatives to Chromate for Corrosion Protection of Aluminum Aerospace Alloys." Prog. Org. Coat., 33 91-100 (1998)

5. Metroke, TL, Parkhill, RL, Knobbe, ET, "Passivation of Metal Alloys Using Sol-Gel-Derived Materials-A Review." Prog. Org. Coat., 41 233-238 (2001)

6. Van Ooij, WJ, et al., "Corrosion Protection Properties of Organofunctional Silanes-An Overview." Tsinghua Sci. Technol., 10 639-664 (2005)

7. Gray, J, Luan, B, "Protective Coatings on Magnesium and Its Alloys-A Critical Review." J. Alloys Compd., 336 88113 (2002)

8. Aegerter, MA, Mennig, M, Sol-Gel Technologies for Glass Producers and Users. Kluwer, Norwell, 2004

9. Dislich, H, "Glassy and Crystalline Systems from Gels: Chemical Basis and Technical Application." J. Non Cryst. Solids, 57 371-388 (1983)

10. Segal, DL, "Sol-Gel Processing: Routes to Oxide Ceramics Using Colloidal Dispersions of Hydrous Oxides and Alkoxide Intermediates." J. Non-Cryst. Solids, 63 183-191 (1984)

11. Brinker, CJ, Scherer, GW, Sol-Gel Science: The Physics and Chemistry of Sol-Gel Processing. Academic Press, San Diego, 1990

12. Pierre, AC, In: Pierre, AC (ed.), Introduction to Sol-Gel Processing, p. 4. Kluwer Academic Publishers, Norwell, 1998

13. Brinker, C, Hurd, A, Schunk, P, Frye, G, "Review of SolGel Thin Film Formation." J. Non Cryst. Solids, 148 424-436 (1992)

14. Hench, LL, West, JK, "The Sol-Gel Process." Chem. Rev., 90 33-72 (1990)

15. Sanchez, C, Belleville, P, Popall, M, Nicole, L, "Hybrid Materials Themed Issue." Chem. Soc. Rev., 40 453-1152 (2011)

16. Sanchez, C, et al., "Designed Hybrid Organic-Inorganic Nanocomposites from Functional Nanobuilding Blocks." Chem. Mater., 13 3061-3083 (2001)

17. Shchukin, DG, Yaremchenko, AA, Ferreira, MGS, Kharton, VV, "Polymer Gel Templating Synthesis of Nanocrystalline Oxide Anodes." Chem. Mater., 17 5124-5129 (2005)

18. Canto, CF, de A. Prado, LAS, Radovanovic, E, Yoshida, IVP, "Organic-Inorganic Hybrid Materials Derived from Epoxy Resin and Polysiloxanes: Synthesis and Characterization." Polym. Eng. Sci., 48 141-148 (2008)

19. Sanchez, C, Ribot, F, "Design of Hybrid Organic-Inorganic Materials Synthesized Via Sol-Gel Chemistry." New J. Chem., 18 1007-1047 (1994)

20. Wojcik, A, Klein, LC, "Transparent Organic/Inorganic Hybrid Gels: A Classification Scheme." Appl. Organomet. Chem., 11 129-135 (1997)

21. José, NM, de A. Prado, LAS, "Materiais Híbridos OrgânicoInorgânicos: Preparação e Algumas Aplicações." Quimica Nova, 28 281-288 (2005)

22. Moreira, SDFC, et al., "Development of New High Transparent Hybrid Organic-Inorganic Monoliths with Surface Engraved Diffraction Pattern." J. Polym. Sci. B, 50 492-499 (2012)

23. Roberge, P, Handbook of Corrosion Engineering. McGrawHill Professional, New York, 1999

24. O'Brien, TF, Bommaraju, TV, Hine, F, Handbook of ChlorAlkali Technology: Volume I: Fundamentals, Volume II: Brine Treatment and Cell Operation, Volume III: Facility Design and Product Handling, Volume IV: Operations, Volume V: Corrosion, Environmental Issues, and Future Developments. Springer, New York, 2007

25. Kaesche, H, Corrosion of Metals: Physicochemical Principles and Current Problems. Springer, Berlin, 2003 
26. Ghali, E, Sastri, VS, Elboujdaini, M, Corrosion Prevention and Protection: Practical Solutions. Wiley, Chichester, 2007

27. Uhlig, HH, Revie, RW, Corrosion and Corrosion Control: An Introduction to Corrosion Science and Engineering. Wiley, New York, 1991

28. Davis, JR, Surface Engineering for Corrosion and Wear Resistance. ASM International Institute of Materials, Materials Park, 2001

29. Pulker, HK, Coatings on Glass. Elsevier, Amsterdam, 1999

30. Sakka, S, Yoko, T, "Sol-Gel-Derived Coating Films and Applications." In: Reisfeld, R, Jørgensen, CK (eds.) Chemistry, Spectroscopy and Applications of Sol-Gel Glasses, Vol. 77, pp. 89-118. Springer, Berlin, 1992

31. Magalhães, JM, Silva, JE, Castro, FP, Labrincha, JA, "Physical and Chemical Characterisation of Metal Finishing Industrial Wastes." J. Environ. Manag., 75 157-166 (2005)

32. Wu, C, Zhang, J, "State-of-Art on Corrosion and Protection of Magnesium Alloys Based on Patent Literatures." Trans. Nonferrous Met. Soc. China, 21 892-902 (2011)

33. Hu, R-G, Zhang, S, Bu, J-F, Lin, C-J, Song, G-L, "Recent Progress in Corrosion Protection of Magnesium Alloys by Organic Coatings." Prog. Org. Coat., 73 129-141 (2012)

34. Schmidt, H, Scholze, H, Kaiser, A, "Principles of Hydrolysis and Condensation Reaction of Alkoxysilanes." J. Non Cryst. Solids, 63 1-11 (1984)

35. Wilkes, GL, Orler, B, Huang, HH, “Ceramers': Hybrid Materials Incorporating Polymeric/Oligomeric Species into Inorganic Glasses Utilizing a Sol-Gel Approach." Polym. Prep., 26 300-302 (1985)

36. Van Ooij, WJ, Sabata, A, "Characterization of Films of Organofunctional Silanes by TOFSIMS and XPS." J. Adhes. Sci. Technol., 5 843-863 (1991)

37. Yuan, W, van Ooij, WJ, "Characterization of Organofunctional Silane Films on Zinc Substrates." J. Colloid Interface Sci., 185 197-209 (1997)

38. Wang, D, Bierwagen, GP, "Sol-Gel Coatings on Metals for Corrosion Protection.” Prog. Org. Coat., 64 327-338 (2009)

39. Mammeri, F, Bourhis, EL, Rozes, L, Sanchez, C, "Mechanical Properties of Hybrid Organic-Inorganic Materials." $J$. Mater. Chem., 153787 (2005)

40. Castelvetro, V, De Vita, C, "Nanostructured Hybrid Materials from Aqueous Polymer Dispersions." Adv. Colloid Interface Sci., 108-109 167-185 (2004)

41. Bescher, E, Mackenzie, JD, "Sol-Gel Coatings for the Protection of Brass and Bronze." J. Sol Gel Sci. Technol., 26 1223-1226 (2003)

42. Attia, SM, Wang, J, Wu, G, Shen, J, Ma, J, "Review on SolGel Derived Coatings: Process, Techniques and Optical Applications." J. Mater. Sci. Technol., 18 211-218 (2002)

43. Mackenzie, JD, Bescher, EP, "Chemical Routes in the Synthesis of Nanomaterials Using the Sol-Gel Process." Acc. Chem. Res., 40 810-818 (2007)

44. Niederberger, M, "Nonaqueous Sol-Gel Routes to Metal Oxide Nanoparticles." Acc. Chem. Res., 40 793-800 (2007)

45. Sakka, S, "Sol-Gel Technology as Representative Processing for Nanomaterials: Case Studies on the Starting Solution." J. Sol Gel Sci. Technol., 46 241-249 (2007)

46. Dimitriev, Y, Ivanova, Y, Iordanova, R, "History of Sol-Gel Science and Technology." J. Univ. Chem. Technol. Metall., 43 181-192 (2008)

47. Kozhukharov, S, "Relationship Between the Conditions of Preparation by the Sol-Gel Route and the Properties of the Obtained Products." J. Univ. Chem. Technol., 44 143-150 (2009)
48. Benvenutti, EV, Moro, CC, Costa, TMH, Gallas, MR, "Materiais híbridos à base de sílica obtidos pelo método Sol-Gel." Quím. Nova, 32 1926-1933 (2009)

49. Pandey, S, Mishra, SB, "Sol-Gel Derived Organic-Inorganic Hybrid Materials: Synthesis, Characterizations and Applications." J. Sol Gel Sci. Technol., 59 73-94 (2011)

50. Balgude, D, Sabnis, A, "Sol-Gel Derived Hybrid Coatings as an Environment Friendly Surface Treatment for Corrosion Protection of Metals and Their Alloys." J. Sol Gel Sci. Technol., 64 124-134 (2012)

51. Abdolah Zadeh, M, van der Zwaag, S, Garcia, SJ, "Routes to Extrinsic and Intrinsic Self-healing Corrosion Protective Sol-Gel Coatings: A Review." Self Heal. Mater., 1 1-18 (2013)

52. Chaturvedi, S, Dave, PN, "Design Process for Nanomaterials." J. Mater. Sci., 48 3605-3622 (2013)

53. Wen, J, Wilkes, GL, "Organic/Inorganic Hybrid Network Materials by the Sol-Gel Approach." Chem. Mater., 8 16671681 (1996)

54. Schottner, G, "Hybrid Sol-Gel-Derived Polymers: Applications of Multifunctional Materials." Chem. Mater., 13 34223435 (2001)

55. Walcarius, A, "Electrochemical Applications of Silica-Based Organic-Inorganic Hybrid Materials." Chem. Mater., 13 3351-3372 (2001)

56. Mitzi, DB, "Thin-Film Deposition of Organic-Inorganic Hybrid Materials." Chem. Mater., 13 3283-3298 (2001)

57. Hay, JN, Raval, HM, "Synthesis of Organic-Inorganic Hybrids Via the Non-hydrolytic Sol-Gel Process." Chem. Mater., 13 3396-3403 (2001)

58. Arkhireeva, A, et al., "Synthesis of Organic-Inorganic Hybrid Particles by Sol-Gel Chemistry." J. Sol Gel Sci. Technol., 31 31-36 (2004)

59. Sanchez, C, Julián, B, Belleville, P, Popall, M, "Applications of Hybrid Organic-Inorganic Nanocomposites." J. Mater. Chem., 153559 (2005)

60. Innocenzi, P, Kidchob, T, Yoko, T, "Hybrid OrganicInorganic Sol-Gel Materials Based on Epoxy-Amine Systems." J. Sol Gel Sci. Technol., 35 225-235 (2005)

61. Dash, S, Mishra, S, Patel, S, Mishra, BK, "Organically Modified Silica: Synthesis and Applications Due to its Surface Interaction with Organic Molecules." Adv. Colloid Interface Sci., 140 77-94 (2008)

62. Lebedev, E, "Hybrid Organo-Inorganic Polymer Systems: Synthesis, Structure and Properties." Theor. Exp. Chem., 46 391-396 (2011)

63. Sanchez, C, et al., "'Chimie douce': A Land of Opportunities for the Designed Construction of Functional Inorganic and Hybrid Organic-Inorganic Nanomaterials." Comptes Rendus Chim., 13 3-39 (2010)

64. Zheng, S, Li, J, "Inorganic-Organic Sol-Gel Hybrid Coatings for Corrosion Protection of Metals." J. Sol Gel Sci. Technol., 54 174-187 (2010)

65. Bramfitt, BL. In: Kutz, M (ed.) Handbook of Materials Selection, pp. 25-65. Wiley Inc., New York, 2007. http:// onlinelibrary.wiley.com/doi/10.1002/9780470172551.ch2/summary

66. Chou, T, et al., "Organic-Inorganic Hybrid Coatings for Corrosion Protection." J. Non Cryst. Solids, 290 153-162 (2001)

67. Kumar, S, Alagar, M, Mohan, V, "Studies on CorrosionResistant Behavior of Siliconized Epoxy Interpenetrating Coatings Over Mild Steel Surface by Electrochemical Methods." J. Mater. Eng. Perform., 11 123-129 (2002) 
68. Chou, T, Chandrasekaran, C, Cao, GZ, "Sol-Gel-Derived Hybrid Coatings for Corrosion Protection." J. Sol Gel Sci. Technol., 26 321-327 (2003)

69. Sayilkan, H, Şener, Ş, Şener, E, "The Sol-Gel Synthesis and Application of Some Anticorrosive Coating Materials." Mater. Sci., 39 106-110 (2003)

70. Gallardo, J, Durán, A, de Damborenea, JJ, “Electrochemical and In Vitro Behaviour of Sol-Gel Coated 316L Stainless Steel." Corros. Sci., 46 795-806 (2004)

71. Gunji, T, Iizuka, Y, Arimitsu, K, Abe, Y, "Preparation and Properties of Alkoxy(methyl)silsesquioxanes as Coating Agents.' J. Polym. Sci. A, 42 3676-3684 (2004)

72. Castro, Y, Ferrari, B, Moreno, R, Durán, A, "Corrosion Behaviour of Silica Hybrid Coatings Produced from Basic Catalysed Particulate Sols by Dipping and EPD.' Surf. Coat. Technol., 191 228-235 (2005)

73. Pepe, A, Galliano, P, Ceré, S, Aparicio, M, Durán, A, "Hybrid Silica Sol-Gel Coatings on Austempered Ductile Iron (ADI)." Mater. Lett., 59 2219-2222 (2005)

74. Mascia, L, Prezzi, L, Wilcox, GD, Lavorgna, M, "Molybdate Doping of Networks in Epoxy-Silica Hybrids: Domain Structuring and Corrosion Inhibition." Prog. Org. Coat., 56 13-22 (2006)

75. Jianguo, L, Gaoping, G, Chuanwei, Y, "Enhancement of the Erosion-Corrosion Resistance of Dacromet with Hybrid $\mathrm{SiO}_{2}$ Sol-Gel." Surf. Coat. Technol., 200 4967-4975 (2006)

76. Pepe, A, Galliano, P, Aparicio, M, Durán, A, Ceré, S, "SolGel Coatings on Carbon Steel: Electrochemical Evaluation." Surf. Coat. Technol., 200 3486-3491 (2006)

77. Xing, W, You, B, Wu, L, "Chemical and Anticorrosion Characterization of Polysilsesquioxane Coatings Catalyzed by Different Acids." J. Coat. Technol. Res., 5 65-72 (2008)

78. Wang, H, Akid, R, "Encapsulated Cerium Nitrate Inhibitors to Provide High-Performance Anti-corrosion Sol-Gel Coatings on Mild Steel." Corros. Sci., 50 1142-1148 (2008)

79. Phanasgaonkar, A, Raja, VS, "Influence of Curing Temperature, Silica Nanoparticles and Cerium on Surface Morphology and Corrosion Behaviour of Hybrid Silane Coatings on Mild Steel." Surf. Coat. Technol., 203 2260-2271 (2009)

80. Qian, M, Mcintosh Soutar, A, Tan, XH, Zeng, XT, Wijesinghe, SL, "Two-Part Epoxy-Siloxane Hybrid Corrosion Protection Coatings for Carbon Steel." Thin Solid Films, 517 5237-5242 (2009)

81. Espinosa-Medina, MA, Carbajal-De la Torre, G, Liu, HB, "Study of Ceramic and Hybrid Coatings Produced by the Sol-Gel Method for Corrosion Protection." Open Corros. J., 2 197-203 (2009)

82. Sarmento, VHV, et al., "Corrosion Protection of Stainless Steel by Polysiloxane Hybrid Coatings Prepared Using the Sol-Gel Process.' Surf. Coat. Technol., 204 2689-2701 (2010)

83. Hosseinalipour, SM, Ershad-langroudi, A, Hayati, AN, Nabizade-Haghighi, AM, "Characterization of Sol-Gel Coated 316L Stainless Steel for Biomedical Applications." Prog. Org. Coat., 67 371-374 (2010)

84. Hammer, P, et al., "Improvement of the Corrosion Resistance of Polysiloxane Hybrid Coatings by Cerium Doping." J. Non Cryst. Solids, 356 2606-2612 (2010)

85. Suegama, PH, et al., "Effect of Cerium(IV) Ions on the Anticorrosion Properties of Siloxane-Poly(methyl methacrylate) Based Film Applied on tin Coated Steel." Electrochim. Acta, 55 5100-5109 (2010)

86. Kiruthika, P, Subasri, R, Jyothirmayi, A, Sarvani, K, Hebalkar, NY, "Effect of Plasma Surface Treatment on Mechanical and Corrosion Protection Properties of UV-Curable SolGel Based GPTS-Z $\mathrm{rO}_{2}$ Coatings on Mild Steel." Surf. Coat. Technol., 204 1270-1276 (2010)
87. Kannan, AG, Choudhury, NR, Dutta, NK, "Electrochemical Performance of Sol-Gel Derived Phospho-silicate-Methacrylate Hybrid Coatings." J. Electroanal. Chem., 641 28-34 (2010)

88. Guin, AK, Nayak, SK, Rout, TK, Bandyopadhyay, N, Sengupta, DK, "Corrosion Behavior of Nanohybrid Titania-Silica Composite Coating on Phosphated Steel Sheet.' J. Coat. Technol. Res., 9 97-106 (2011)

89. Hernández-Escolano, M, et al., "The Design and Characterisation of Sol-Gel Coatings for the Controlled-Release of Active Molecules." J. Sol Gel Sci. Technol., 64 442-451 (2012)

90. Ahmad, S, Zafar, F, Sharmin, E, Garg, N, Kashif, M, "Synthesis and Characterization of Corrosion Protective Polyurethanefattyamide/Silica Hybrid Coating Material." Prog. Org. Coat., 73 112-117 (2012)

91. Kim, H, Hwang, T, "Corrosion Protection Enhancement Effect by Mixed Silica Nanoparticles of Different Sizes Incorporated in a Sol-Gel Silica Film." J. Sol Gel Sci. Technol., 63 563-568 (2012)

92. Arunchandran, C, Ramya, S, George, RP, Mudali, UK, "Self-Healing Corrosion Resistive Coatings Based on Inhibitor Loaded $\mathrm{TiO}_{2}$ Nanocontainers." J. Electrochem. Soc., 159 C552-C559 (2012)

93. Hammer, P, dos Santos, FC, Cerrutti, BM, Pulcinelli, SH, Santilli, CV, "Highly Corrosion Resistant Siloxane-Polymethyl Methacrylate Hybrid Coatings." J. Sol Gel Sci. Technol., 63 266-274 (2012)

94. Cambon, J-B, Ansart, F, Bonino, J-P, Turq, V, "Effect of Cerium Concentration on Corrosion Resistance and Polymerization of Hybrid Sol-Gel Coating on Martensitic Stainless Steel." Prog. Org. Coat., 75 486-493 (2012)

95. Joncoux-Chabrol, K, Bonino, J-P, Gressier, M, Menu, M-J, Pébère, N, "Improvement of Barrier Properties of a Hybrid Sol-Gel Coating by Incorporation of Synthetic Talc-Like Phyllosilicates for Corrosion Protection of a Carbon Steel." Surf. Coat. Technol., 206 2884-2891 (2012)

96. Sakai, RT, et al., "Electrochemical Study of TEOS, TEOS/ MPTS, MPTS/MMA and TEOS/MPTS/MMA Films on Tin Coated Steel in $3.5 \% \mathrm{NaCl}$ Solution." Prog. Org. Coat., 74 288-301 (2012)

97. Subasri, R, Malathi, R, Jyothirmayi, A, Hebalkar, NY, "Synthesis and Characterization of CuO-Hybrid Silica Nanocomposite Coatings on SS 304." Ceram. Int., 38 57315740 (2012)

98. Kumar, N, Jyothirmayi, A, Soma Raju, KRC, Subasri, R, "Effect Of Functional Groups (Methyl, Phenyl) on OrganicInorganic Hybrid Sol-Gel Silica Coatings on Surface Modified SS 316." Ceram. Int., 38 6565-6572 (2012)

99. Zandi-zand, R, Verbeken, K, Adriaens, A, "Corrosion Resistance Performance of Cerium Doped Silica Sol-Gel Coatings on 304L Stainless Steel." Prog. Org. Coat., 75 463473 (2012)

100. Angel-López, D, et al., "Analysis of Degradation Process During the Incorporation of $\mathrm{ZrO}_{2}: \mathrm{SiO}_{2}$ Ceramic Nanostructures into Polyurethane Coatings for the Corrosion Protection of Carbon Steel." J. Mater. Sci., 48 1067-1084 (2012)

101. Certhoux, E, et al., "New Sol-Gel Formulations to Increase the Barrier Effect of a Protective Coating Against the Corrosion of Steels." Prog. Org. Coat., 76 165-172 (2013)

102. Hammer, P, dos Santos, FC, Cerrutti, BM, Pulcinelli, SH, Santilli, CV, "Carbon Nanotube-Reinforced SiloxanePMMA Hybrid Coatings with High Corrosion Resistance." Prog. Org. Coat., 76 601-608 (2013) 
103. Rahoui, S, Turq, V, Bonino, J-P, "Effect of Thermal Treatment on Mechanical and Tribological Properties of hybrid Coatings Deposited by Sol-Gel Route on Stainless Steel." Surf. Coat. Technol., 235 15-23 (2013)

104. Fedel, M, et al., "Effect of Na-Montmorillonite Sonication on the Protective Properties of Hybrid Silica Coatings." Electrochim. Acta, (2013). doi:10.1016/j.electacta.2013.11.006

105. Jeeva Jothi, K, Palanivelu, K, "Synergistic Effect of Silane Modified Nanocomposites for Active Corrosion Protection." Ceram. Int., 39 7619-7625 (2013)

106. Peng, S, et al., "Preparation of Anticorrosion Hybrid Silica Sol-Gel Coating Using $\mathrm{Ce}\left(\mathrm{NO}_{3}\right)_{3}$ As Catalyst." J. Sol Gel Sci. Technol., 66 133-138 (2013)

107. Balgude, D, Konge, K, Sabnis, A, "Synthesis and Characterization of Sol-Gel Derived CNSL Based Hybrid Anti-corrosive Coatings." J. Sol Gel Sci. Technol., (2013). doi:10.1007/s10971-013-3198-z

108. Santana, I, Pepe, A, Jimenez-Pique, E, Pellice, S, Ceré, S, "Silica-Based Hybrid Coatings for Corrosion Protection of Carbon Steel. Part I: Effect of Pretreatment with Phosphoric Acid." Surf. Coat. Technol., 236 476-484 (2013)

109. Hernandez, M, et al., "Characterization of Hybrid Sol-Gel Coatings Doped with Hydrotalcite-Like. Compounds on Steel and Stainless Steel Alloys." ECS Trans., 47 195-206 (2013)

110. Chawada, G, Dholakiya, BZ, "Organic-Inorganic Hybrid Sol-Gel Pretreatments for Corrosion Protection of Mild Steel in Neutral and Acidic Solutions." Res. Chem. Intermed., (2013). doi:10.1007/s11164-013-1479-3

111. Karmakar, B, De, G, Ganguli, D, "Dense Silica Microspheres from Organic and Inorganic Acid Hydrolysis." $J$. Non Cryst. Solids, 272 119-126 (2000)

112. Wagh, PB, Rao, AV, Haranath, D, "Influence of Molar Ratios of Precursor, Solvent and Water on Physical Properties of Citric Acid Catalyzed TEOS Silica Aerogels." Mater. Chem. Phys., 53 41-47 (1998)

113. Kunst, SR, et al., "Corrosion Resistance of SiloxanePoly(methyl methacrylate) Hybrid Films Modified with Acetic Acid on Tin Plate Substrates: Influence of Tetraethoxysilane Addition." Appl. Surf. Sci., (2013). doi:10.1016/j.apsusc.2013.09.182

114. Wojcik, AB, Klein, LC, “Transparent Inorganic/organic Copolymers by the Sol-Gel Process: Copolymers of Tetraethyl Orthosilicate (TEOS), Vinyl Triethoxysilane (VTES) and (Meth)acrylate Monomers." J. Sol Gel Sci. Technol., 4 57-66 (1995)

115. Álvarez, D, Collazo, A, Hernández, M, Nóvoa, XR, Pérez, C, "Characterization of Hybrid Sol-Gel Coatings Doped with Hydrotalcite-Like Compounds to Improve Corrosion Resistance of AA2024-T3 Alloys." Prog. Org. Coat., 67 152-160 (2010)

116. Parkhill, R, Knobbe, E, Donley, M, "Application and Evaluation of Environmentally Compliant Spray-Coated Ormosil Films as Corrosion Resistant Treatments for Aluminum 2024-T3." Prog. Org. Coat., 41 261-265 (2001)

117. Kasten, LS, et al., "An XPS Study of Cerium Dopants In Sol-Gel Coatings for Aluminum 2024-T3." Surf. Coat. Technol., 140 11-15 (2001)

118. Metroke, T, Kachurina, O, Knobbe, ET, "Spectroscopic and Corrosion Resistance Characterization of GLYMOTEOS Ormosil Coatings for Aluminum Alloy Corrosion Inhibition." Prog. Org. Coat., 44 295-305 (2002)

119. Metroke, T, Kachurina, O, "Spectroscopic and Corrosion Resistance Characterization of Amine and Super AcidCured Hybrid Organic-Inorganic Thin Films on 2024-T3 Aluminum Alloy." Prog. Org. Coat., 44 185-199 (2002)
120. Voevodin, N, Balbyshev, V, Khobaib, M, Donley, M, "Nanostructured Coatings Approach for Corrosion Protection." Prog. Org. Coat., 47 416-423 (2003)

121. Conde, A, Durán, A, de Damborenea, J, "Polymeric SolGel Coatings as Protective Layers of Aluminium Alloys." Prog. Org. Coat., 46 288-296 (2003)

122. Donley, MS, et al., "The Self-assembled Nanophase Particle (SNAP) Process: A Nanoscience Approach to Coatings." Prog. Org. Coat., 47 401-415 (2003)

123. Metroke, TL, Gandhi, JS, Apblett, A, "Corrosion Resistance Properties of Ormosil Coatings on 2024-T3 Aluminum Alloy." Prog. Org. Coat., 50 231-246 (2004)

124. Metroke, TL, Apblett, A, "Effect of Solvent Dilution on Corrosion Protective Properties of Ormosil Coatings on 2024-T3 Aluminum Alloy." Prog. Org. Coat., 51 36-46 (2004)

125. Zandi-zand, R, Ershad-langroudi, A, Rahimi, A, "Silica Based Organic-Inorganic Hybrid Nanocomposite Coatings for Corrosion Protection." Prog. Org. Coat., 53 286$291(2005)$

126. Zandi-zand, R, Ershad-langroudi, A, Rahimi, A, "Organic-Inorganic Hybrid Coatings for Corrosion Protection of 1050 Aluminum Alloy." J. Non Cryst. Solids, 351 13071311 (2005)

127. Donley, MS, Balbyshev, VN, Voevodin, NN, "Self-assembled NAnophase Particle (SNAP) Surface Treatments for Corrosion Protection of AA2024-T3." Prog. Org. Coat., 52 34-38 (2005)

128. Liu, Y, Sun, D, You, H, Chung, JS, “Corrosion Resistance Properties of Organic-Inorganic Hybrid Coatings on 2024 Aluminum Alloy." Appl. Surf. Sci., 246 82-89 (2005)

129. Khramov, AN, Voevodin, NN, Balbyshev, VN, Mantz, RA, "Sol-Gel-Derived Corrosion-Protective Coatings with Controllable Release of Incorporated Organic Corrosion Inhibitors." Thin Solid Films, 483 191-196 (2005)

130. Zheludkevich, M, et al., "Nanostructured Sol-Gel Coatings Doped with Cerium Nitrate as Pre-treatments for AA2024-T3. Corrosion Protection Performance." Electrochim. Acta, 51 208-217 (2005)

131. Voevodin, NN, Balbyshev, VN, Donley, MS, "Investigation of Corrosion Protection Performance of Sol-Gel Coatings on AA2024-T3." Prog. Org. Coat., 52 28-33 (2005)

132. Zheludkevich, ML, Serra, R, Montemor, MF, Salvado, IMM, Ferreira, MGS, "Corrosion Protective Properties of Nanostructured Sol-Gel Hybrid Coatings to AA2024-T3." Surf. Coat. Technol., 200 3084-3094 (2006)

133. Voevodin, NN, Kurdziel, JW, Mantz, R, "Corrosion Protection for Aerospace Aluminum Alloys by Modified Self-assembled NAnophase Particle (MSNAP) Sol-Gel." Surf. Coat. Technol., 201 1080-1084 (2006)

134. Wu, KH, Chang, TC, Yang, CC, Wang, GP, "Dynamics and Corrosion Resistance of Amine-cured Organically Modified Silicate Coatings on Aluminum Alloys." Thin Solid Films, 513 84-89 (2006)

135. Vezir Kahraman, M, Kuğu, M, Menceloğlu, Y, KayamanApohan, N, Güngör, A, "The Novel Use of Organo Alkoxy Silane for the Synthesis of Organic-Inorganic Hybrid Coatings." J. Non Cryst. Solids, 352 2143-2151 (2006)

136. Wu, KH, Li, MC, Yang, CC, Wang, GP, "Domain Size and Thermal Stability of Amine-cured Hybrid Films as Corrosion Resistance Treatments for Aluminum Alloy." $J$. Non Cryst. Solids, 352 2897-2904 (2006)

137. Han, Y-H, Taylor, A, Mantle, MD, Knowles, KM, "UV Curing of Organic-Inorganic Hybrid Coating Materials." J. Sol Gel Sci. Technol., 43 111-123 (2007) 
138. Wang, H, Akid, R, "A Room Temperature Cured Sol-Gel Anticorrosion Pre-treatment for Al 2024-T3 Alloys." Corros. Sci., 49 4491-4503 (2007)

139. Wu, KH, Chao, CM, Yeh, TF, Chang, TC, “Thermal Stability and Corrosion Resistance of Polysiloxane Coatings on 2024-T3 and 6061-T6 Aluminum Alloy." Surf. Coat. Technol., 201 5782-5788 (2007)

140. Pathak, SS, Khanna, AS, Sinha, TJM, "HMMM Cured Corrosion Resistance Waterborne Ormosil Coating for Aluminum Alloy." Prog. Org. Coat., 60 211-218 (2007)

141. Barkhudarov, PM, et al., "Corrosion Inhibition Using Superhydrophobic Films." Corros. Sci., 50 897-902 (2008)

142. Lampke, T, Darwich, S, Nickel, D, Wielage, B, "Development and Characterization of Sol-Gel Composite Coatings on Aluminum Alloys for Corrosion Protection." Mater. Werkst., 39 914-919 (2008)

143. Tiwari, A, Zhu, J, Hihara, LH, "The Development of Low-Temperature Hardening Silicone Ceramer Coatings for the Corrosion Protection of Metals." Surf. Coat. Technol., 202 4620-4635 (2008)

144. Poznyak, SK, et al., "Preparation and Corrosion Protective Properties of Nanostructured Titania-Containing Hybrid Sol-Gel Coatings on AA2024." Prog. Org. Coat., 62 226-235 (2008)

145. Yasakau, KA, Zheludkevich, ML, Karavai, OV, Ferreira, MGS, "Influence of Inhibitor Addition on the Corrosion Protection Performance of Sol-Gel Coatings on AA2024." Prog. Org. Coat., 63 352-361 (2008)

146. Rosero-Navarro, NC, Pellice, SA, Durán, A, Aparicio, M, "Effects of Ce-containing Sol-Gel Coatings Reinforced with $\mathrm{SiO}_{2}$ Nanoparticles on the Protection of AA2024." Corros. Sci., 50 1283-1291 (2008)

147. Vreugdenhil, AJ, Gelling, VJ, Woods, ME, Schmelz, JR, Enderson, BP, "The Role of Crosslinkers in EpoxyAmine Crosslinked Silicon Sol-Gel Barrier Protection Coatings." Thin Solid Films, 517 538-543 (2008)

148. Pathak, SS, Khanna, AS, "Synthesis and Performance Evaluation of Environmentally Compliant Epoxysilane Coatings for Aluminum Alloy." Prog. Org. Coat., 62 409416 (2008)

149. Wang, D, Chen, X, Zhang, X, Liu, Y, Hu, L, "Enhancement Corrosion Resistance of (3-Methacryloxypropyl)silsesquioxane Hybrid Films and Its Validation by GasMolecule Diffusion Coefficients Using MD Simulation." $J$. Sol Gel Sci. Technol., 49 293-300 (2008)

150. Rosero-Navarro, NC, Pellice, SA, Castro, Y, Aparicio, M, Durán, A, "Improved Corrosion Resistance of AA2024 Alloys Through Hybrid Organic-Inorganic Sol-Gel Coatings Produced from Sols with Controlled Polymerisation." Surf. Coat. Technol., 203 1897-1903 (2009)

151. Pathak, SS, Khanna, AS, "Investigation of Anti-corrosion Behavior of Waterborne Organosilane-Polyester Coatings for AA6011 Aluminum Alloy." Prog. Org. Coat., 65 288294 (2009)

152. Rosero-Navarro, NC, Pellice, SA, Durán, A, Ceré, S, Aparicio, M, "Corrosion Protection of Aluminium Alloy AA2024 with Cerium Doped Methacrylate-Silica Coatings." J. Sol Gel Sci. Technol., 52 31-40 (2009)

153. Pirhady Tavandashti, N, Sanjabi, S, Shahrabi, T, "Corrosion Protection Evaluation of Silica/Epoxy Hybrid Nanocomposite Coatings to AA2024." Prog. Org. Coat., 65 182186 (2009)

154. Schem, M, et al., " $\mathrm{CeO}_{2}$-Filled Sol-Gel Coatings for Corrosion Protection of AA2024-T3 Aluminium Alloy." Corros. Sci., 51 2304-2315 (2009)
155. Raps, D, et al., "Electrochemical Study of InhibitorContaining Organic-Inorganic Hybrid Coatings on AA2024." Corros. Sci., 51 1012-1021 (2009)

156. Li, Y-S, Lu, W, Wang, Y, Tran, T, "Studies of (3Mercaptopropyl)trimethoxylsilane and Bis(trimethoxysilyl)ethane Sol-Gel Coating on Copper and Aluminum." Spectrochim. Acta A, 73 922-928 (2009)

157. Kakde, V, Mannari, V, "Advanced Chrome-Free Organic-Inorganic Hybrid Pretreatments for Aerospace Aluminum Alloy 2024-T3-Application of Novel Bis-ureasil Sol-Gel Precursors." J. Coat. Technol. Res., 6 201-211 (2009)

158. Rosero-Navarro, NC, et al., "Optimization of Hybrid SolGel Coatings by Combination of Layers with Complementary Properties for Corrosion Protection of AA2024." Prog. Org. Coat., 69 167-174 (2010)

159. Álvarez, P, Collazo, A, Covelo, A, Nóvoa, XR, Pérez, C, "The Electrochemical Behaviour of Sol-Gel Hybrid Coatings Applied on AA2024-T3 Alloy: Effect of the Metallic Surface Treatment." Prog. Org. Coat., 69 175-183 (2010)

160. Varma, PCR, et al., "Corrosion Protection of AA 2024-T3 Aluminium Alloys Using 3,4-Diaminobenzoic Acid Chelated Zirconium-Silane Hybrid Sol-Gels." Thin Solid Films, 518 5753-5761 (2010)

161. Shi, H, Liu, F, Han, E, "Corrosion Behaviour of Sol-Gel Coatings Doped with Cerium Salts on 2024-T3 Aluminum Alloy." Mater. Chem. Phys., 124 291-297 (2010)

162. Shi, H, Liu, F, Han, E, "Characterization of Self-assembled Nano-phase Silane-Based Particle Coating." Trans. Nonferrous Met. Soc. China, 20 1928-1935 (2010)

163. Becchi, DM, Luca, MA, Martinelli, M, Mitidieri, S, "Organic-Inorganic Coatings Based on Epoxidised Castor Oil/APTES/TEOS." J. Am. Oil Chem. Soc., 88 101-109 (2010)

164. Feng, Z, Liu, Y, Thompson, GE, Skeldon, P, "Sol-Gel Coatings for Corrosion Protection of 1050 Aluminium Alloy." Electrochim. Acta, 55 3518-3527 (2010)

165. Tiwari, A, Hihara, LH, "High Performance ReactionInduced Quasi-ceramic Silicone Conversion Coating for Corrosion Protection of Aluminium Alloys." Prog. Org. Coat., 69 16-25 (2010)

166. Kumar, A, Kanta, A, Birbilis, N, Williams, T, Muddle, BCA, "Pseudoboehmite-Silane Hybrid Coating for Enhanced Corrosion Protection of AA2024-T3." J. Electrochem. Soc., 157 C346 (2010)

167. Collazo, A, Hernández, M, Nóvoa, XR, Pérez, C, "Effect of the Addition of Thermally Activated Hydrotalcite on the Protective Features of Sol-Gel Coatings Applied on AA2024 Aluminium Alloys." Electrochim. Acta, 56 78057814 (2011)

168. Wittmar, A, Wittmar, M, Caparrotti, H, Veith, M, "The Influence of the Inhibitor Particle Sizes to the Corrosion Properties of Hybrid Sol-Gel Coatings." J. Sol Gel Sci. Technol., 59 621-628 (2011)

169. Croes, KJ, et al., "An Electrochemical Study of Corrosion Protection by In Situ Oxidative Polymerization in Phenylenediamine Crosslinked Sol-Gel Hybrid Coatings." Electrochim. Acta, 56 7796-7804 (2011)

170. Roussi, E, Tsetsekou, A, Tsiourvas, D, Karantonis, A, "Novel Hybrid Organo-Silicate Corrosion Resistant Coatings Based on Hyperbranched Polymers." Surf. Coat. Technol., 205 3235-3244 (2011)

171. Varma, PCR, Periyat, P, Oubaha, M, McDonagh, C, Duffy, B, "Application of Niobium Enriched Ormosils as 
Thermally Stable Coatings for Aerospace Aluminium Alloys." Surf. Coat. Technol., 205 3992-3998 (2011)

172. Cambon, J-B, et al., "Effect of Cerium on Structure Modifications of a Hybrid Sol-Gel Coating, Its Mechanical Properties and Anti-corrosion Behavior." Mater. Res. Bull., 47 3170-3176 (2012)

173. Iroh, JO, Rajamani, D, "Synthesis and Structure of Environmentally Friendly Hybrid Clay/Organosilane Nanocomposite Coatings." J. Inorg. Organomet. Polym. Mater., 22 595-603 (2012)

174. Wittmar, A, Wittmar, M, Ulrich, A, Caparrotti, H, Veith, M, "Hybrid Sol-Gel Coatings Doped with Transition Metal Ions for the Protection of AA 2024-T3." J. Sol Gel Sci. Technol., 61 600-612 (2012)

175. Kozhukharov, S, et al., "Protective Ability of Hybrid Nano-composite Coatings with Cerium Sulphate as Inhibitor Against Corrosion of AA2024 Aluminium Alloy." Prog. Org. Coat., 73 95-103 (2012)

176. Dias, SAS, Lamaka, SV, Nogueira, CA, Diamantino, TC, Ferreira, MGS, "Sol-Gel Coatings Modified with Zeolite Fillers for Active Corrosion Protection of AA2024." Corros. Sci., 62 153-162 (2012)

177. Dias, SAS, et al., "The Role of Ce(III)-Enriched Zeolites on the Corrosion Protection of AA2024-T3." Electrochim. Acta, 112 549-556 (2013)

178. Collazo, A, Covelo, A, Nóvoa, XR, Pérez, C, "Corrosion Protection Performance of Sol-Gel Coatings Doped with Red Mud Applied on AA2024-T3." Prog. Org. Coat., 74 334-342 (2012)

179. Gupta, G, Pathak, SS, Khanna, AS, "Anticorrosion Performance of Eco-friendly Silane Primer for Coil Coating Applications." Prog. Org. Coat., 74 106-114 (2012)

180. Abuín, M, Serrano, A, Llopis, J, García, MA, Carmona, N, "Silica Doped with Lanthanum Sol-Gel Thin Films for Corrosion Protection." Thin Solid Films, 520 5267-5271 (2012)

181. Mekeridis, ED, Kartsonakis, IA, Kordas, GC, "Multilayer Organic-Inorganic Coating Incorporating $\mathrm{TiO}_{2}$ Nanocontainers Loaded with Inhibitors for Corrosion Protection of AA2024-T3." Prog. Org. Coat., 73 142-148 (2012)

182. Hojjati Najafabadi, A, Mozaffarinia, R, Rahimi, H, Shoja Razavi, R, Paimozd, E, "Sol-Gel Processing of Hybrid Nanocomposite Protective Coatings Using Experimental Design." Prog. Org. Coat., 76 293-301 (2013)

183. May, M, Wang, H, Akid, R, "Bond Strength of Hybrid Sol-Gel Coatings with Different Additives." J. Coat. Technol. Res., 10 407-413 (2012)

184. Yasakau, KA, Kallip, S, Zheludkevich, ML, Ferreira, MGS, "Active Corrosion Protection of AA2024 by SolGel Coatings with Cerium Molybdate Nanowires." Electrochim. Acta, 112 236-246 (2013)

185. Roussi, E, Tsetsekou, A, Skarmoutsou, A, Charitidis, CA, Karantonis, A, "Anticorrosion and Nanomechanical Performance of Hybrid Organo-silicate Coatings Integrating Corrosion Inhibitors." Surf. Coat. Technol., 232 131-141 (2013)

186. Wankhede, RG, Morey, S, Khanna, AS, Birbilis, N, "Development of Water-Repellent Organic-Inorganic Hybrid Sol-Gel Coatings on Aluminum Using Short Chain Perfluoro Polymer Emulsion." Appl. Surf. Sci., 283 1051-1059 (2013)

187. Naderi, R, Fedel, M, Deflorian, F, Poelman, M, Olivier, M, "Synergistic Effect of Clay Nanoparticles and Cerium Component on the Corrosion Behavior of Eco-friendly
Silane Sol-Gel Layer Applied on Pure Aluminum." Surf. Coat. Technol., 224 93-100 (2013)

188. Capelossi, VR, et al., "Corrosion Protection of CLAD 2024 Aluminum Alloy Anodized in Tartaric-Sulfuric Acid Bath and Protected with Hybrid Sol-Gel Coating." Electrochim. Acta, (2013). doi:10.1016/j.electacta.2013.09.004

189. Rahimi, H, Mozaffarinia, R, Hojjatinajafabadi, A, "Corrosion and Wear Resistance Characterization of Environmentally Friendly Sol-Gel Hybrid Nanocomposite Coating on AA5083." J. Mater. Sci. Technol., 29 603-608 (2013)

190. Lakshmi, RV, Yoganandan, G, Kavya, KT, Basu, BJ, "Effective Corrosion Inhibition Performance of $\mathrm{Ce}^{3+}$ Doped Sol-Gel Nanocomposite Coating on Aluminum Alloy." Prog. Org. Coat., 76 367-374 (2013)

191. Rahimi, H, Mozaffarinia, R, Hojjati Najafabadi, A, Shoja Razavi, R, Paimozd, E, "Optimization of Process Factors for the Synthesis of Advanced Chrome-Free Nanocomposite Sol-Gel Coatings for Corrosion Protection of Marine Aluminum Alloy AA5083 by Design of Experiment." Prog. Org. Coat., 76 307-317 (2013)

192. Bechi, DM, Luca, MAD, Martinelli, M, Mitidieri, S, "Organic-Inorganic Coatings Based on Epoxidized Castor Oil with APTES/TIP and TEOS/TIP." Prog. Org. Coat., 76 736-742 (2013)

193. Zheludkevich, ML, et al., "Active Protection Coatings with Layered Double Hydroxide Nanocontainers of Corrosion Inhibitor." Corros. Sci., 52 602-611 (2010)

194. Shchukin, DG, et al., "Active Anticorrosion Coatings with Halloysite Nanocontainers." J. Phys. Chem. C, 112 958964 (2008)

195. Zheludkevich, ML, Shchukin, DG, Yasakau, KA, Möhwald, H, Ferreira, MGS, "Anticorrosion Coatings with Self-healing Effect Based on Nanocontainers Impregnated with Corrosion Inhibitor." Chem. Mater., 19 402-411 (2007)

196. Tan, ALK, Soutar, AM, "Hybrid Sol-Gel Coatings for Corrosion Protection of Copper." Thin Solid Films, 516 5706-5709 (2008)

197. Peng, S, et al., "The Enhancement of Benzotriazole on Epoxy Functionalized Silica Sol-Gel Coating for Copper Protection." Appl. Surf. Sci., 276 284-290 (2013)

198. Kiele, E, et al., "Methyl-Modified Hybrid Organic-Inorganic Coatings for the Conservation of Copper." J. Cult. Herit., (2013). doi:10.1016/j.culher.2013.06.002

199. Gusakov, AG, Voropayev, AG, Zheludkevich, ML, Vecher, AA, Raspopov, SA, "Studies of the Interaction of Copper with Atomic and Molecular Oxygen." Phys. Chem. Chem. Phys., 1 5311-5314 (1999)

200. Honkanen, M, Hoikkanen, M, Vippola, M, Vuorinen, J, Lepistö, T, “Aminofunctional Silane Layers for Improved Copper-Polymer Interface Adhesion." J. Mater. Sci., 46 6618-6626 (2011)

201. Yang, JC, Kolasa, B, Gibson, JM, Yeadon, M, "Selflimiting Oxidation of Copper." Appl. Phys. Lett., 73 28412843 (1998)

202. Deflorian, F, Rossi, S, Fedrizzi, L, Fedel, M, "Integrated Electrochemical Approach for the Investigation of Silane Pre-treatments for Painting Copper." Prog. Org. Coat., 63 338-344 (2008)

203. Finšgar, M, Milošev, I, "Inhibition of Copper Corrosion by 1,2,3-Benzotriazole: A Review." Corros. Sci., 52 27372749 (2010)

204. González, S, Gil, M, Hernández, J, Fox, V, Souto, R, "Resistance to Corrosion of Galvanized Steel Covered 
with an Epoxy-Polyamide Primer Coating." Prog. Org. Coat., 41 167-170 (2001)

205. Garcia-Heras, M, et al., "Preparation and Electrochemical Study of Cerium-Silica Sol-Gel Thin Films." J. Alloys Compd., 380 219-224 (2004)

206. Eliziane, M, et al., "Characterization of Organic-Inorganic Hybrid Coatings for Corrosion Protection of Galvanized Steel and Electroplated ZnFe Steel 2. Experimental Procedure." Mater. Res., 9 59-64 (2006)

207. Conde, A, Damborenea, J, Durán, A, Menning, M, "Protective Properties of a Sol-Gel Coating on Zinc Coated Steel.', J. Sol Gel Sci. Technol., 37 79-85 (2006)

208. Fedel, M, et al., "Corrosion Protection Properties of Silane Pre-treated Powder Coated Galvanized Steel." Prog. Org. Coat., 66 118-128 (2009)

209. Deflorian, F, Rossi, S, Fedel, M, Motte, C, "Electrochemical Investigation of High-Performance Silane Sol-Gel Films Containing Clay Nanoparticles." Prog. Org. Coat., 69 158-166 (2010)

210. Fedel, M, et al., "Compatibility Between Cataphoretic Electro-coating and Silane Surface Layer for the Corrosion Protection of Galvanized Steel." Prog. Org. Coat., 69 118-125 (2010)

211. Motte, C, et al., "Improvement of Corrosion Protection Offered to Galvanized Steel by Incorporation of Lanthanide Modified Nanoclays in Silane Layer." Prog. Org. Coat., 74 326-333 (2012)

212. Kartsonakis, IA, Balaskas, AC, Koumoulos, EP, Charitidis, CA, Kordas, GC, "Incorporation of Ceramic Nanocontainers into Epoxy Coatings for the Corrosion Protection of Hot Dip Galvanized Steel." Corros. Sci., 57 30-41 (2012)

213. Zand, RZ, Verbeken, K, Adriaens, A, "Influence of the Cerium Concentration on the Corrosion Performance of Ce-Doped Silica Hybrid Coatings on Hot Dip Galvanized Steel Substrates." Int. J. Electrochem. Sci., 8549 (2013)

214. Xue, D, Van Ooij, WJ, "Corrosion Performance Improvement of Hot-Dipped Galvanized (HDG) Steels by Electro-deposition of Epoxy-Resin-Ester Modified Bis-[triethoxy-silyl] ethane (BTSE) Coatings." Prog. Org. Coat., 76 1095-1102 (2013)

215. Figueira, RB, Silva, CJ, Pereira, EV, Salta, MM, "Ureasilicate Hybrid Coatings for Corrosion Protection of Galvanized Steel in Cementitious Media." J. Electrochem. Soc., 160 C467-C479 (2013)

216. Magalhães, AAO, Margarit, ICP, Mattos, OR, "Molybdate Conversion Coatings on Zinc Surfaces." J. Electroanal. Chem., 572 433-440 (2004)

217. Lin, B-L, Lu, J-T, Kong, G, "Effect of Molybdate Postsealing on the Corrosion Resistance of Zinc Phosphate Coatings on Hot-Dip Galvanized Steel." Corros. Sci., 50 962-967 (2008)

218. Da Silva, CG, et al., "The Molybdate-Zinc Conversion Process." Corros. Sci., 51 151-158 (2009)

219. Moutarlier, V, Gigandet, MP, Ricq, L, Pagetti, J, "Electrochemical Characterisation of Anodic Oxidation Films Formed in Presence of Corrosion Inhibitors." Appl. Surf. Sci., 183 1-9 (2001)

220. Bibber, JW, "Non-chrome-Containing Conversion Coatings for Zinc and Zinc Alloys: Environmentally Friendly Alternatives Provide Equal or Better Adhesion and Corrosion Resistance as Conventional Methods." Met. Finish., 106 41-46 (2008)

221. Hara, M, Ichino, R, Okido, M, Wada, N, "Corrosion Protection Property of Colloidal Silicate Film on Galvanized Steel.' Surf. Coat. Technol., 169-170 679-681 (2003)
222. Dalbin, S, Maurin, G, Nogueira, RP, Persello, J, Pommier, $\mathrm{N}$, "Silica-Based Coating for Corrosion Protection of Electrogalvanized Steel." Surf. Coat. Technol., 194 363371 (2005)

223. Socha, RP, Fransaer, J, "Mechanism of Formation of Silica-Silicate Thin Films on Zinc." Thin Solid Films, 488 45-55 (2005)

224. Socha, RP, Pommier, N, Fransaer, J, "Effect of Deposition Conditions on the Formation of Silica-Silicate Thin Films.' Surf. Coat. Technol., 201 5960-5966 (2007)

225. Klimow, G, Fink, N, Grundmeier, G, "Electrochemical Studies of the Inhibition of the Cathodic Delamination of Organically Coated Galvanised Steel by Thin Conversion Films." Electrochim. Acta, 53 1290-1299 (2007)

226. Zhu, L, Yang, F, Ding, N, "Corrosion Resistance of the Electro-galvanized Steel Treated in a Titanium Conversion Solution." Surf. Coat. Technol., 201 7829-7834 (2007)

227. Hosseini, M, Ashassi-Sorkhabi, H, Ghiasvand, HAY, "Corrosion Protection of Electro-Galvanized Steel by Green Conversion Coatings." J. Rare Earths, 25 537-543 (2007)

228. Bernal, S, et al., "Lanthanide Salts as Alternative Corrosion Inhibitors.” J. Alloys Compd., 225 638-641 (1995)

229. Arenas, MA, Casado, C, Damborenea, JD, "Influence of the Conversion Coating on the Corrosion of Galvanized Reinforcing Steel." Cem. Concr. Compos., 28 267-275 (2007)

230. Hinton, BRW, "Corrosion Inhibition with Rare Earth Metal Salts.” J. Alloys Compd., 180 15-25 (1992)

231. Van de Leest, RE, Krijl, G, "A Tungstate Conversion Coating on Tin." Thin Solid Films, 72 237-246 (1980)

232. Da Silva, CG, Correia, AN, de Lima-Neto, P, Margarit, ICP, Mattos, OR, "Study of Conversion Coatings Obtained from Tungstate-Phosphoric Acid Solutions." Corros. Sci., 47 709-722 (2005)

233. Zou, Z, Li, N, Li, D, Liu, H, Mu, S, “A Vanadium-Based Conversion Coating as Chromate Replacement for Electrogalvanized Steel Substrates." J. Alloys Compd., 509 503-507 (2011)

234. Tan, ALK, Soutar, AM, Annergren, IF, Liu, YN, "Multilayer Sol-Gel Coatings for Corrosion Protection of Magnesium." Surf. Coat. Technol., 198 478-482 (2005)

235. Khramov, AN, Balbyshev, VN, Kasten, LS, Mantz, RA, "Sol-Gel Coatings with Phosphonate Functionalities for Surface Modification of Magnesium Alloys." Thin Solid Films, 514 174-181 (2006)

236. Lamaka, SV, et al., "Novel Hybrid Sol-Gel Coatings for Corrosion Protection of AZ31B Magnesium Alloy." Electrochim. Acta, 53 4773-4783 (2008)

237. Khramov, AN, Johnson, JA, "Phosphonate-Functionalized ORMOSIL Coatings for Magnesium Alloys." Prog. Org. Coat., 65 381-385 (2009)

238. Guo, X, An, M, Yang, P, Su, C, Zhou, Y, "Property Characterization and Formation Mechanism of Anticorrosion Film Coated on AZ31B Mg Alloy by SNAP Technology." J. Sol Gel Sci. Technol., 52 335-347 (2009)

239. Shi, H, Liu, F, Han, E, "Corrosion Protection of AZ91D Magnesium Alloy with Sol-Gel Coating Containing 2Methyl Piperidine." Prog. Org. Coat., 66 183-191 (2009)

240. Hu, J, Li, Q, Zhong, X, Zhang, L, Chen, B, "Composite Anticorrosion Coatings for AZ91D Magnesium Alloy with Molybdate Conversion Coating and Silicon Sol-Gel Coatings.” Prog. Org. Coat., 66 199-205 (2009)

241. Galio, AF, et al., "Inhibitor-Doped Sol-Gel Coatings for Corrosion Protection of Magnesium Alloy AZ31." Surf. Coat. Technol., 204 1479-1486 (2010) 
242. Barranco, V, et al., "Electrochemical Study of Tailored Sol-Gel Thin Films as Pre-treatment Prior to Organic Coating for AZ91 Magnesium Alloy." Prog. Org. Coat., 68 347-355 (2010)

243. Zhong, X, et al., "Effect of Cerium Concentration on Microstructure, Morphology and Corrosion Resistance of Cerium-Silica Hybrid Coatings on Magnesium Alloy AZ91D." Prog. Org. Coat., 69 52-56 (2010)

244. Nikrooz, B, Zandrahimi, M, "Optimization of Process Variables and Corrosion Properties of a Multi-layer Silica Sol-Gel Coating on AZ91D Using the Box-Behnken Design.” J. Sol Gel Sci. Technol., 59 640-649 (2011)

245. Zomorodian, A, et al., "Anti-corrosion Performance of a New Silane Coating for Corrosion Protection of AZ31 Magnesium Alloy in Hank's Solution." Surf. Coat. Technol., 206 4368-4375 (2012)

246. Murillo-Gutiérrez, NV, Ansart, F, Bonino, J-P, Menu, MJ, Gressier, M, "Protection Against Corrosion of Magnesium Alloys with Both Conversion Layer and Sol-Gel Coating." Surf. Coat. Technol., 232 606-615 (2013)

247. Brusciotti, F, et al., "Hybrid Epoxy-Silane Coatings for Improved Corrosion Protection of $\mathrm{Mg}$ Alloy." Corros. Sci., 67 82-90 (2013)

248. Molnár, P, Ostapovets, A, Jäger, A, "Reversible Motion of Twin Boundaries in AZ31 Alloy and New Design of Magnesium Alloys as Smart Materials." Mater. Des., 56 509-516 (2014)

249. Alam, ME, Hamouda, AMS, Nguyen, QB, Gupta, M, "Improving Microstructural and Mechanical Response of New AZ41 and AZ51 Magnesium Alloys Through Simultaneous Addition of Nano-sized $\mathrm{Al}_{2} \mathrm{O}_{3}$ Particulates and Ca." J. Alloys Compd., 574 565-572 (2013)

250. Li, ZM, et al., "Improved High Cycle Fatigue Properties of a New Magnesium Alloy." Mater. Sci. Eng. A, 582 170177 (2013)

251. Jiang, J, et al., "Microstructure and Mechanical Properties of AZ61 Magnesium Alloy Parts Achieved by Thixoextruding Semisolid Billets Prepared by New SIMA." Trans. Nonferrous Met. Soc. China, 23 576-585 (2013)

252. Pan, F, et al., "Key R\&D Activities for Development of New Types of Wrought Magnesium Alloys in China." Trans. Nonferrous Met. Soc. China, 20 1249-1258 (2010)

253. Alam, ME, Han, S, Nguyen, QB, Salem Hamouda, AM, Gupta, M, "Development of New Magnesium Based Alloys and Their Nanocomposites." J. Alloys Compd., 509 8522-8529 (2011)

254. Chen, TJ, Wang, W, Zhang, DH, Ma, Y, Hao, Y, "Development of a New Magnesium Alloy ZW21." Mater. Des., 44 555-565 (2013)

255. Sendova, M, Willis, K, "Spiral and Curved Periodic Crack Patterns in Sol-Gel Films." Appl. Phys. Mater. Sci. Process., 76 957-959 (2003)

256. Latellaa, BA, Barbéa, CJ, Cassidya, DJ, Lia, H, Ignatb, M, "Mechanical Stability and Decohesion of Sol-Gel Hybrid Coatings on Metallic Substrates." Rev. Matér., 10 199-204 (2005)

257. Castro, Y, Ferrari, B, Moreno, R, "Silica Sol-Gel Coatings on Metals Produced by EPD." J. Sol Gel Sci. Technol., 26 735-739 (2003)
258. Arkles, B, “Commercial Application of Sol-Gel-Derived Hybrid Materials." MRS Bull., 26 402-408 (2001)

259. Ghosh, SK. In: Ghosh, SK (ed.) Self-healing Materials, pp. 1-28. Wiley-VCH Verlag GmbH \& Co. KGaA, Weinheim, 2008. http://onlinelibrary.wiley.com/doi/10.1002/978352762 5376.ch1/summary

260. Trabelsi, W, Cecilio, P, Ferreira, MGS, Montemor, MF, "Electrochemical Assessment of the Self-healing Properties of Ce-Doped Silane Solutions for the Pre-treatment of Galvanised Steel Substrates." Prog. Org. Coat., 54 276-284 (2005)

261. Shchukin, DG, Zheludkevich, M, Möhwald, H, "Feedback Active Coatings Based on Incorporated Nanocontainers." J. Mater. Chem., 16 4561-4566 (2006)

262. Lamaka, SV, et al., "TiOx Self-assembled Networks Prepared by Templating Approach as Nanostructured Reservoirs for Self-healing Anticorrosion Pre-treatments." Electrochem. Commun., 8 421-428 (2006)

263. Lamaka, SV, et al., "Nanoporous Titania Interlayer as Reservoir of Corrosion Inhibitors for Coatings with Selfhealing Ability." Prog. Org. Coat., 58 127-135 (2007)

264. Yabuki, A, Yamagami, H, Noishiki, K, "Barrier and Selfhealing Abilities of Corrosion Protective Polymer Coatings and Metal Powders for Aluminum Alloys." Mater. Corros., 58 497-501 (2007)

265. Montemor, MF, et al., "The synergistic Combination of Bis-silane and $\mathrm{CeO}_{2} \cdot \mathrm{ZrO}_{2}$ Nanoparticles on the Electrochemical Behaviour of Galvanised Steel in $\mathrm{NaCl}$ Solutions." Electrochim. Acta, 53 5913-5922 (2008)

266. Montemor, MF, Pinto, R, Ferreira, MGS, "Chemical Composition and Corrosion Protection of Silane Films Modified with $\mathrm{CeO}_{2}$ Nanoparticles." Electrochim. Acta, 54 5179-5189 (2009)

267. Cho, SH, White, SR, Braun, PV, "Self-healing Polymer Coatings." Adv. Mater., 21 645-649 (2009)

268. Zheludkevich, ML, et al., "Self-healing Protective Coatings with 'Green' Chitosan Based Pre-layer Reservoir of Corrosion Inhibitor." J. Mater. Chem., 21 4805-4812 (2011)

269. García, SJ, et al., "Self-healing Anticorrosive Organic Coating Based on an Encapsulated Water Reactive Silyl Ester: Synthesis and Proof of Concept." Prog. Org. Coat., 70 142-149 (2011)

270. Odom, SA, Esser-Kahn, AP, Sottos, NR, White, SR, Moore, JS, "Triggered Release from Polymer Capsules." Macromolecules, 44 5539-5553 (2011)

271. Carneiro, J, et al., "Chitosan-Based Self-Healing Protective Coatings Doped with Cerium Nitrate for Corrosion Protection of Aluminum Alloy 2024." Prog. Org. Coat., 75 8-13 (2012)

272. Zheludkevich, ML, Tedim, J, Ferreira, MGS, "'Smart' Coatings for Active Corrosion Protection Based on Multifunctional Micro and Nanocontainers." Electrochim. Acta, 82 314-323 (2012)

273. Hughes, AE, Cole, IS, Muster, TH, Varley, RJ, "Designing Green, Self-healing Coatings for Metal Protection." NPG Asia Mater., 2 143-151 (2010)

274. White, SR, et al., "Autonomic Healing of Polymer Composites." Nature, 409 794-797 (2001) 